\title{
Modeling of Sorption Enhanced Steam Methane Reforming in an adiabatic fixed bed reactor
}

\author{
J.R. Fernandez ${ }^{\mathrm{a},}{ }^{,}$, J.C. Abanades ${ }^{\mathrm{a}}$, R. Murillo ${ }^{\mathrm{b}}$ \\ ${ }^{a}$ Instituto Nacional del Carbón, CSIC-INCAR Spanish Research Council, C/ Francisco Pintado Fe, 26, \\ 33011, Oviedo. Spain. \\ ${ }^{\mathrm{b}}$ Instituto de Carboquímica, CSIC-ICB Spanish Research Council, C/ Miguel Luesma Castán 4, 50015, \\ Zaragoza. Spain. \\ Dr. Jose Ramon Fernandez (corresponding author). Instituto Nacional del Carbón, (CSIC), Francisco \\ Pintado Fe, 26, 33011 Oviedo, Spain. \\ Tel. +34985118980; Fax. +34985297662; e-mail address: jramon@incar.csic.es
}

\begin{abstract}
Sorption enhanced methane reforming (SER), employing a CaO-based solid as a high temperature $\mathrm{CO}_{2}$ sorbent, is generally considered to be a promising route for $\mathrm{H}_{2}$ production. In this paper we present a dynamic pseudo-homogeneous model to describe the operation of a packed bed reactor in which the SER reaction is carried out under adiabatic conditions. This reactor can be implemented according to several process schemes, including a novel $\mathrm{Ca} / \mathrm{Cu}$ looping process for hydrogen generation with inherent $\mathrm{CO}_{2}$ capture. The proposed SER model is based on the well-established principles of gas-solid contact and heat transfer in fixed-bed reactors and on the kinetic expressions published in the literature that describe the main reactions involved in the process. The resulting model describes the transient performance of the SER reaction and confirms the theoretical viability of this critical reaction stage in a large scale $\mathrm{H}_{2}$ production facility. It is demonstrated that the SER process can yield a $\mathrm{CH}_{4}$ conversion
\end{abstract}


and $\mathrm{H}_{2}$ purity of up to $85 \%$ and $95 \%$, respectively, under operating conditions of $923 \mathrm{~K}$, 3.5 MPa, a steam/carbon ratio of 5 and a space velocity of $3.5 \mathrm{~kg} / \mathrm{m}^{2} \mathrm{~s}$.

Keywords: $\mathrm{CO}_{2}$ capture; carbonation; packed bed; catalysis; chemical reactors; dynamic simulation

\section{Introduction}

Hydrogen is an important raw material in the chemical and petroleum industries. It can also be used as a clean source of energy for electricity generation, which will lead to a huge increase in the demand for hydrogen in the future. There is also considerable interest worldwide in developing new $\mathrm{CO}_{2}$ capture technologies focused on the mitigation of climate change (Metz et al., 2005). These conditions will serve as a stimulus for developing new processes for large scale hydrogen production from fossil fuels in combination with $\mathrm{CO}_{2}$ capture ("pre-combustion" $\mathrm{CO}_{2}$ capture systems), in order to reduce the energy penalty and the costs traditionally associated with the $\mathrm{CO}_{2}$ capture process.

Steam methane reforming (SMR) is nowadays the main process for large-scale production of hydrogen (Rostrup-Nielsen et al., 2002). The first stage of this heterogeneous catalytic process is usually performed at high temperature and pressure (typically $1073 \mathrm{~K}-1273 \mathrm{~K}$ and $2 \mathrm{MPa}-3.5 \mathrm{MPa}$ ), followed by an additional shift reaction at a lower temperature (around $473 \mathrm{~K}-673 \mathrm{~K}$ ) in order to maximize the $\mathrm{H}_{2}$ yield. However, both the reforming and water gas shift reactions are equilibrium limited, so that it is not possible to achieve the complete conversion of $\mathrm{CH}_{4}$ and $\mathrm{CO}$ in a single stage under the usual reactor conditions. If the $\mathrm{CO}_{2}$ is removed from the product gas as soon as is it formed, the normal equilibrium is displaced in favor of the hydrogen yield 
in accordance with Le Chatelier's principle, so almost complete conversion can be achieved.

In the sorption enhanced reforming process (SER) a $\mathrm{CO}_{2}$ sorbent is used, together with a reforming catalyst in the same reactor, to remove $\mathrm{CO}_{2}$ from the gas phase (Hufton et al., 1999; Harrison, 2008). When using $\mathrm{CaO}$ as sorbent in the reforming process, higher methane and $\mathrm{CO}$ conversions can be attained at lower temperatures (around $923 \mathrm{~K}$ ) and a product that contains more than $95 \% \mathrm{H}_{2}$ (dry basis) is possible (Balasubramanian et al., 1999). Additional benefits derivable from the SER process with $\mathrm{CaO}$ are the minimization of the coking potential, the elimination of the downstream $\mathrm{H}_{2}$ purification steps, the diminution of excess steam in the reforming operation, and the reduction of $\mathrm{CO}$ in the gas effluent to ppm levels (Lopez Ortiz and Harrison, 1999; Lee et al., 2004; Yi and Harrison, 2005; Yoon et al., 2007; Li and Cai, 2007; Harrison, 2008; Lysikov et al., 2008; Martavaltzi and Lemonidou, 2010).

The SER process with $\mathrm{CaO}$ as $\mathrm{CO}_{2}$-sorbent is slightly exothermic so that no additional energy is required to produce hydrogen. CaO-based sorbents are commonly used in SER because they are able to reduce $\mathrm{CO}_{2}$ to very low concentrations at moderate temperatures (823-973 K). Calcium oxide may be the most technically and economically viable option because it can be obtained from a wide range of abundant, natural and inexpensive sources including limestone, dolomite and calcium hydroxide (Florin and Harris, 2008). However, it is well known that $\mathrm{CaO}$ from natural limestones undergoes a rapid loss of reactivity after several carbonation/calcination cycles (Abanades, 2002). Nevertheless, there are numerous reports in the literature on $\mathrm{CaO}-$ based synthetic materials for applications similar to SER, in which a high residual activity ( $>0.3$ mol fraction) is maintained even after a large number of 
carbonation/calcination cycles (Stevens et al., 2007; Manovic and Anthony, 2008; Manovic and Anthony, 2009; Blamey et al., 2010).

In the present paper, we report on the development of a dynamic pseudohomogeneous reactor model to analyze the SER reaction on a large scale $(10 \mathrm{~kg} / \mathrm{s}$ of $\mathrm{CH}_{4}$ fed into the reformer reactor) and investigate the most suitable material parameters and reactor conditions for its optimum performance. The model was constructed to suit the boundary conditions imposed by the new $\mathrm{Ca} / \mathrm{Cu}$ looping process described in Abanades et al. (2010) and Fernández et al. (2012), but it should also be applicable to other processes, based on the Sorption Enhanced Reforming principles. Several important modeling works on sorption enhanced reforming have been published in recent years that may be useful purposes of comparison. Xiu et al. (2002) developed a theoretical model that simulates a SER process under non-isothermal, non-adiabatic, and non-isobaric conditions. Mass and thermal dispersion in the axial direction were considered, with negligible radial gradients. They achieved a product gas stream with $\mathrm{H}_{2}$ purity of $88 \%$ (dry basis) with only small traces of $\mathrm{CO}_{2}$ and $\mathrm{CO}$, at operating conditions of $723 \mathrm{~K}, 0.45 \mathrm{MPa}$, a steam/carbon ratio of 6 and a feed gas velocity of 0.08 $\mathrm{m} / \mathrm{s}$. Lee et al. (2004) devised a dynamic pseudo-homogeneous and non-adiabatic model for SER with $\mathrm{CaO}$ as the $\mathrm{CO}_{2}$ acceptor. They found that $\mathrm{H}_{2}$ purity is sensitive to the temperature of the wall, pressure and feed composition. Rusten et al. (2007) simulated a SER operation carried out in a fixed-bed reactor with lithium zirconate as $\mathrm{CO}_{2}$ sorbent using a transient one-dimensional model with axial dispersion. More recent works in which sorption enhanced reforming has been theoretically and experimentally investigated in order to interpret experimental results from small laboratory scale reactors include those of Li and Cai (2007) and Reijers et al. (2009). However, to our knowledge, there is no modeling work on SER reactor performance under adiabatic 
conditions, the most natural choice for large scale reactor designs, since adiabatic conditions would make it possible to take full advantage of the thermal neutrality of the overall SER reaction. Furthermore, a smaller number of adiabatic reactors with a larger cross-sectional area (with respect to the state-of-the-art multitubular reforming reactors) would avoid the need to install costly heat transfer equipment around the reactors.

In this paper we describe the performance on a large scale of an adiabatic sorption enhanced reforming reactor using a multi-component system with a pressure drop and overall mass and energy balances. The validity of the model's predictions was checked by comparing the simulated results with experimental data taken from the literature (Lee et al. 2004; Li and Cai 2007). Furthermore, a sensitivity analysis of the model's predictions for the main material properties (carbonation reaction rate constant and $\mathrm{CaO}$ sorbent capacity) was also carried out. A simulation of the SER reactor's performance is carried out in part II of this work in order to determine the operational window that would ensure optimal performance of the SER process in terms of $\mathrm{H}_{2}$ yield and $\mathrm{CH}_{4}$ conversion. The effect of the principal operating conditions such as steam/carbon ratio, temperature, total pressure and catalyst/sorbent ratio is also analyzed.

\section{Mathematical model description}

The SER reactor operation must be described using a dynamic model due to the time-dependent nature of $\mathrm{CO}_{2}$ capture, as shown in Fig. 1. The reaction front that evolves with time generates a gas composition as a function of the operating conditions in the reaction front. The main chemical reactions that participate in the steam methane reforming are as follows:

$$
\begin{array}{ll}
\mathrm{CH}_{4}(\mathrm{~g})+\mathrm{H}_{2} \mathrm{O}(\mathrm{g}) \leftrightarrows \mathrm{CO}(\mathrm{g})+3 \mathrm{H}_{2}(\mathrm{~g}) & \Delta \mathrm{H}_{298 \mathrm{~K}}=+206.2 \mathrm{~kJ} / \mathrm{mol} \\
\mathrm{CH}_{4}(\mathrm{~g})+2 \mathrm{H}_{2} \mathrm{O}(\mathrm{g}) \leftrightarrows \mathrm{CO}_{2}(\mathrm{~g})+4 \mathrm{H}_{2}(\mathrm{~g}) & \Delta \mathrm{H}_{298 \mathrm{~K}}=+164.9 \mathrm{~kJ} / \mathrm{mol}
\end{array}
$$




$$
\mathrm{CO}(\mathrm{g})+\mathrm{H}_{2} \mathrm{O}(\mathrm{g}) \leftrightarrows \mathrm{CO}_{2}(\mathrm{~g})+\mathrm{H}_{2}(\mathrm{~g}) \quad \Delta \mathrm{H}_{298 \mathrm{~K}}=-41.5 \mathrm{~kJ} / \mathrm{mol}
$$

Reactions (I) and (II) are highly endothermic, so they are favored by high temperatures, while the water gas shift reaction (III) is exothermic and therefore it is promoted by low temperatures. As pointed out above, in the sorption enhanced reforming (SER) based on CaO-based sorbents, $\mathrm{CO}_{2}$ is removed as it is formed by reacting with the active calcium oxide, reaction (IV). This reaction is also highly exothermic, so that the enthalpy of the overall reaction is almost neutral, reaction (V).

$$
\begin{array}{ll}
\mathrm{CaO}(\mathrm{s})+\mathrm{CO}_{2}(\mathrm{~g}) \leftrightarrows \mathrm{CaCO}_{3}(\mathrm{~s}) & \Delta \mathrm{H}_{298 \mathrm{~K}}=-178.8 \mathrm{~kJ} / \mathrm{mol} \\
\mathrm{CH}_{4}(\mathrm{~g})+\mathrm{CaO}(\mathrm{s})+2 \mathrm{H}_{2} \mathrm{O}(\mathrm{g}) \leftrightarrows \mathrm{CaCO} 3(\mathrm{~s})+4 \mathrm{H}_{2}(\mathrm{~g}) & \Delta \mathrm{H}_{298 \mathrm{~K}}=-13.9 \mathrm{~kJ} / \mathrm{mol}
\end{array}
$$

The reactor model has been designed for adiabatic conditions so that it can profit from the thermal neutrality of the overall SER reaction by using $\mathrm{CaO}$ as a regenerable $\mathrm{CO}_{2}$ sorbent (reaction $\mathrm{V}$ ). Moreover, an ideal plug flow pattern is assumed while the reactor is operating. This plug flow assumption is based on the high velocities that can be expected in a large scale reactor. The design will be such as to maximize the reactor capacity per unit of cross-sectional area and high superficial gas velocities will be used (typically higher than $0.5 \mathrm{~m} / \mathrm{s}$ ), as generally occurs in conventional large-scale reforming reactors (Dybkjaer, 1995; Rostrup-Nielsen et al., 2002).

Following the criteria in the dispersion model reported by Levenspiel (1979) and considering the operating conditions listed in Table 3 , the Peclet number $\left(\mathrm{Pe}=\mathrm{uL} / \mathrm{D}_{\mathrm{e}}\right)$ is higher than 800 , so that the degree of dispersion of the gas flowing through the reactor will be minimal and a plug flow can be considered reasonable for the SER performance described in this work. 
Superficial gas velocities higher than $0.5 \mathrm{~m} / \mathrm{s}$ also lead to a high turbulent regime and therefore high mass and heat transfer coefficients between gas and solids can be assumed. Using the physical properties and operating conditions presented in Table 2 and Table 3, a gas-solid heat transfer coefficient $\left(\mathrm{h}_{\mathrm{fs}}\right)$ of about $0.13 \mathrm{~kW} / \mathrm{m}^{2} \mathrm{~K}$ is obtained (Dixon, 1979; Borman et al., 1992). This value implies a very fast gas-solid transfer with no appreciable difference between the gas and solid temperatures at any point in the reactor. Because of the similarities between the equations governing heat and mass transfer, the gas-solid mass transfer coefficients $\left(\mathrm{k}_{\mathrm{fs}}\right)$ can be calculated by means of analogous correlations to those employed to estimate heat transfer coefficients. For the conditions employed in this work, a gas-solid mass transfer coefficient of about 0.17 m/s was obtained (McCabe et al., 1985). Therefore, a rapid gas-solid mass transfer inside the matrix of the solid bed during the SER operation can be assumed, as reported by Breault (2006).

In summary, plug flow without axial dispersion may be assumed as a reasonable representation of the flow pattern in the large scale SER reactor used in this work. Moreover, the interparticle concentration and temperature gradients can be considered negligible at the scale of several millimeters, as is the case in large scale conventional reformers. An ideal gas behavior, a constant bed void fraction, a uniform particle size for the reactor-packed materials, a perfect mixing of the catalyst and sorbent pellets and a negligible catalyst deactivation were also assumed for this model.

The kinetics of the key reforming and shift reactions were obtained using the Langmuir-Hinshelwood equations reported by $\mathrm{Xu}$ and Froment (1989). This reaction kinetic model can be expressed as: 


$$
\begin{aligned}
& \mathrm{R}_{1}=\frac{1}{(D E N)^{2}} \frac{k_{1}}{p_{H_{2}}^{2 \mathrm{E}}}\left(\mathrm{p}_{\mathrm{CH}_{4}} \mathrm{p}_{\mathrm{H}_{2} \mathrm{O}}-\frac{\mathrm{p}_{\mathrm{H}_{8}}^{8} \mathrm{p}_{\mathrm{CO}}}{\mathrm{K}_{1}}\right) \\
& \mathrm{R}_{2}=\frac{1}{(D E N)^{2}} \frac{k_{2}}{p_{H_{2}}^{\mathrm{g} E}}\left(\mathrm{p}_{\mathrm{CH}_{4}} \mathrm{p}_{\mathrm{H}_{2} \mathrm{O}}^{2}-\frac{\mathrm{p}_{\mathrm{H}_{8}}^{4} \mathrm{P}^{\mathrm{P}} \mathrm{CO}_{\mathrm{R}}}{\mathrm{K}_{2}}\right) \\
& \mathrm{R}_{\mathrm{g}}=\frac{1}{(D E N)^{2}} \frac{k_{\mathrm{g}}}{p_{\mathrm{H}_{\mathrm{g}}}}\left(\mathrm{p}_{\mathrm{CO}} \mathrm{p}_{\mathrm{H}_{\mathrm{g}} \mathrm{O}}-\frac{\mathrm{p}_{\mathrm{H}_{\mathrm{g}}} \mathrm{p}_{\mathrm{CO2} 2}}{\mathrm{~K}_{\mathrm{g}}}\right) \\
& \mathrm{DEN}=1+K_{C O} \mathrm{P}_{\mathrm{CO}}+\mathrm{K}_{\mathrm{H2}} \mathrm{p}_{\mathrm{H2}}+\mathrm{K}_{\mathrm{CH4}} \mathrm{P}_{\mathrm{CH} 4}+\mathrm{K}_{\mathrm{H} 2 \mathrm{O}} \frac{\mathrm{n}_{\mathrm{H} 2 \mathrm{O}}}{\mathrm{p}_{\mathrm{H} 2}}
\end{aligned}
$$

where $\mathrm{p}_{\mathrm{i}}=\mathrm{x}_{\mathrm{i}} \mathrm{P}\left(\mathrm{i}=\mathrm{CH}_{4}, \mathrm{H}_{2} \mathrm{O}, \mathrm{H}_{2}, \mathrm{CO}_{2}, \mathrm{CO}, \mathrm{P}\right.$ is the total pressure and $\mathrm{x}_{\mathrm{i}}$ the gas-phase mole fraction of component i), $\mathrm{k}_{1}, \mathrm{k}_{2}$ and $\mathrm{k}_{3}$ are the rate constants, and $\mathrm{K}_{1}, \mathrm{~K}_{2}$ and $\mathrm{K}_{3}$ are the equilibrium constants. The expressions of these parameters are listed in Table 1.

According to Eq. (1 to 3), the rate of consumption and formation of component i, $r_{i}$ $\left(\mathrm{kmol} / \mathrm{kg}_{\mathrm{cat}} \mathrm{s}\right)$ can be calculated as follows:

$\mathrm{r}_{\mathrm{i}}=\sum_{j=1}^{\mathrm{d}} \varphi_{i j} R_{j} \quad$ (i=1-5 component, $\left.\mathrm{j}=1-3\right)$

where $\varphi_{\mathrm{ij}}$ is the stoichiometric coefficient of component $\mathrm{i}$. If $\mathrm{i}$ refers to a reactant, $\varphi_{\mathrm{ij}}$ is negative, and if i refers to a product, $\varphi_{\mathrm{ij}}$ is positive. From this it follows that the rate of consumption or formation for each component is:

$$
\begin{aligned}
& \mathrm{r}_{\mathrm{CH} 4}=-\mathrm{R}_{1}-\mathrm{R}_{2} \\
& \mathrm{r}_{\mathrm{H} 2 \mathrm{O}}=-\mathrm{R}_{1}-2 \mathrm{R}_{2}-\mathrm{R}_{3} \\
& \mathrm{r}_{\mathrm{H} 2}=3 \mathrm{R}_{1}+4 \mathrm{R}_{2}+\mathrm{R}_{3} \\
& \mathrm{r}_{\mathrm{CO} 2}=\mathrm{R}_{2}+\mathrm{R}_{3} \\
& \mathrm{r}_{\mathrm{CO}}=\mathrm{R}_{1}-\mathrm{R}_{3}
\end{aligned}
$$


To describe the carbonation kinetics of $\mathrm{CaO}$-based sorbents, many expressions have been reported in the literature (Bathia and Perlmuter 1983; Lee et al., 2004; Li and Cai, 2007; Grasa et al., 2008; Grasa et al., 2009). For this work we have chosen the empirical equation used by Rodriguez et al. (2011) to interpret the pilot results from the capture of $\mathrm{CO}_{2}$ by $\mathrm{CaO}$, for which a first-order carbonation reaction rate is assumed:

$$
\frac{d X}{d t}=k_{\text {oarb }}\left(X_{\max }-X\right)\left(v_{C O 2}-v_{c o 2, e q}\right)
$$

where $\mathrm{k}_{\text {carb }}$ is the reaction rate constant of active $\mathrm{CaO}$ (determined as $0.35 \mathrm{~s}^{-1}$ ), $\mathrm{X}_{\max }$ is the maximum carbonation conversion of $\mathrm{CaO}$, and $v_{\mathrm{CO} 2}$ and $v_{\mathrm{CO} 2 \text {,eq }}$ are the gas-phase mole fraction and the equilibrium mole fraction of $\mathrm{CO}_{2}$ in the reactor, respectively. Likewise, $\mathrm{k}_{\mathrm{carb}}$ can be considered to be independent of the temperature in the range of temperatures used in this paper, which is consistent with earlier studies published by Bhatia and Perlmutter (1983) and more recent works (Dennis and Hayhurst, 1987; Li and Cai, 2007). The volume fraction of $\mathrm{CO}_{2}$ in the equilibrium can be estimated using Eq. (7) (Baker, 1962).

$$
v_{\text {rn } A \text { 月 }}=4.137 \cdot 10^{7} \exp \left(\frac{-20474}{T}\right)
$$

The molar rate of $\mathrm{CO}_{2}$ removed per unit mass of $\mathrm{CaO}, \mathrm{r}_{\text {carb }}\left(\mathrm{kmol} / \mathrm{kg}_{\text {cat }} \mathrm{s}\right)$, can be calculated from Eq. (8), where $\mathrm{M}_{\mathrm{CaO}}$ is the molecular weight of $\mathrm{CaO}$.

$$
r_{\sigma a r b}=\frac{\eta}{M_{a \pi \ell}}\left(\frac{d X}{d t}\right)
$$

On the basis of the assumptions outlined above, the pseudo-homogeneous model of the differential mass balance for a packed bed can be written as:

$$
\varepsilon \frac{\partial \mathrm{C}_{\mathrm{i}}}{\partial \mathrm{t}}=\frac{\partial(\mathrm{u} \mathrm{C})}{\partial \mathrm{z}}+\eta(1-a) \rho_{\mathrm{cat}} r_{t}-(1-a) \rho_{\mathrm{CaO}} r_{\mathrm{carb}}
$$


where $C_{i}$ is the molar concentration of species $i, \varepsilon$ is the bed void fraction, $u$ is the superficial velocity, $\eta$ is the effectiveness factor for both reforming and carbonation reactions, $\rho_{\text {cat }}$ and $\rho_{\mathrm{CaO}}$ are the apparent densities of the catalyst and $\mathrm{CaO}$, respectively. An effectiveness factor of about 0.3 was considered in order to tackle possible diffusion resistance in the gas-solid reactions involved in the SER process. This assumption is consistent with the results obtained in SER operations with large pellets (up to $0.007 \mathrm{~m}$ ) at high pressure (Solsvik and Jakobsen, 2011). The last term on the right of Eq. (9) is not zero only for the $\mathrm{CO}_{2}$ mass balance and represents the molar rate of $\mathrm{CO}_{2}$ removed by the carbonation of $\mathrm{CaO}$ per unit bed-volume of the reactor.

The pseudo-homogeneous energy balance for an adiabatic packed bed reactor according to a plug flow pattern can be expressed as:

$$
\begin{aligned}
& {\left[(1-\varepsilon) \rho_{s} C_{p g}+\varepsilon \rho_{g} C_{p g}\right] \frac{\partial T}{\partial t}=-\frac{\partial\left(u \rho_{g} c_{p g} T\right)}{\partial z}-} \\
& -(1-a) \rho_{c a t} \Sigma \eta \mathbb{R}_{j} H_{R V}-(1-a) \rho_{c a O} r_{c a r b} H_{c a r b}
\end{aligned}
$$

where $\rho_{\mathrm{s}}$ is the average apparent density of the solids in the reactor, $\rho_{\mathrm{g}}$ is the gas phase density and $c_{p s}$ and $c_{p g}$ are the solid and gas heat capacities, respectively. $\mathrm{H}_{\mathrm{Rj}}$ represents the heat of reaction $\mathrm{j}$ in reactions (I) to (III) and $\mathrm{H}_{\text {carb }}$ represents the heat of the $\mathrm{CaO}$ carbonation reaction in reaction (IV).

The distribution of pressure $(\mathrm{MPa} / \mathrm{m})$ along the packed bed can be described by the Ergun equation as follows (Ergun, 1952).

$$
\begin{aligned}
& \frac{\mathrm{dP}}{\mathrm{dz}}=-\left[K_{D} u-K_{V} u^{2}\right] 10^{-\mathrm{s}} \\
& K_{D}=\frac{150 \mu_{\mathrm{v}}(1-\mathrm{\varepsilon})^{2}}{d_{\mathrm{p}}^{2} a^{2}}
\end{aligned}
$$


$K_{Y}=\frac{1.75(1-\varepsilon)}{d_{p}^{l} s^{8}} \frac{M_{g} P}{0.082 T}$

where $\mathrm{P}$ is the local pressure at the axial coordinate, $\mathrm{K}_{\mathrm{D}}$ and $\mathrm{K}_{\mathrm{V}}$ are parameters corresponding to the viscous and the kinetic pressure loss terms, $u$ is the superficial velocity, $\mu_{g}$ is the viscosity of the fluid, $\varepsilon$ is the bed porosity, $d_{p}$ is the particle diameter. $\mathrm{M}_{\mathrm{g}}$ is the molecular weight of the gas and $\mathrm{T}$ is the local temperature.

The mathematical model is mainly composed of partial differential equations, algebraic equations, and initial and boundary conditions. The model has been implemented and solved using MATLAB programming software. The partial differential equations, Eq. (9) (one for each component $\mathrm{i}=\mathrm{CH}_{4}, \mathrm{H}_{2} \mathrm{O}, \mathrm{H}_{2}, \mathrm{CO}_{2}, \mathrm{CO}$ ) and Eq. (10) were converted to a set of ordinary differential equations with initial conditions by discretizing the spatial derivative in axial direction (z) employing backward finite differences. For example, a typical bed reactor length of $7 \mathrm{~m}$ long was divided into 39 sections with 40 nodes and the resulting predictions were virtually identical with further increases in the number of nodes.

The initial and boundary conditions in Eqs. (11), (12) and (13) are as follows:

$$
\begin{array}{lll}
\mathrm{C}_{\mathrm{i}}=\mathrm{C}_{\mathrm{i}, 0} & \mathrm{~T}=\mathrm{T}_{0} & \text { at } \mathrm{t}=0 \\
\mathrm{C}_{\mathrm{i}}=\mathrm{C}_{\mathrm{i}, \text { in }} & \mathrm{T}=\mathrm{T}_{\text {in }} & \mathrm{P}=\mathrm{P}_{\text {in }} \quad \text { at } \mathrm{z}=0
\end{array}
$$

The initial concentrations of the gas species in the reactor should be set to zero, but they were actually considered as equal to $10^{-6}$ in order to avoid denominators equal to zero in the equations described above. The system formed by the ordinary differential equations and the other algebraic equations mentioned above was simultaneously solved employing the "ode15s.m" function, which is a MATLAB tool for solving initial value problems for stiff ordinary differential equations. 
The model predictions were first checked for consistency at different operating conditions by closing all the mass and energy balances involved in the process for different times during a complete SER cycle. Equilibrium conditions were reached during the SER performance (prebreakthrough) and during the SMR operation (postbreakthrough), when considering fast reforming and carbonation kinetics. As mentioned above, we are not aware of any published works on sorption enhanced reforming processes performed in adiabatic fixed-bed reactors. For this reason, the model had to be validated by comparing our simulation results with experimental data taken from previous works on SER in non-adiabatic and non-isothermal fixed-bed reactors (Lee et al. 2004; Li and Cai 2007). For this validation, the model developed in this paper was adapted slightly to the conditions established in the above mentioned works. An additional term on the right side of the energy balance, Eq. (10), was included in order to account for the heat transfer through the reactor wall when an external source of energy is supplied to a non-adiabatic system:

$$
\begin{aligned}
& {\left[(1-z) p_{s} c_{p s}+\varepsilon_{g} p_{p g}\right] \frac{\partial T}{\partial t}--\frac{\partial\left(u \rho_{\mathrm{g}} c_{p g} T\right)}{\partial z}-} \\
& -(1-s) \rho_{c a t} \Sigma \eta R_{1} H_{E V}-(1-s) \rho_{c a Q} r_{c a r b} H_{c a r b}+h_{w}\left(T_{w}-T\right) \frac{4}{D_{r}}
\end{aligned}
$$

where $h_{w}$ is the heat transfer coefficient through the reactor wall, $T_{w}$ is the reactor wall temperature and $D_{r}$ is the inner diameter of the reforming reactor. Moreover, the carbonation kinetics employed in these works was also taken into account for the validation of the model. In the simulations, the operating temperature was varied between $923 \mathrm{~K}$ and $1023 \mathrm{~K}$, the operating pressure between $0.1 \mathrm{MPa}$ and $1.5 \mathrm{MPa}$, the $\mathrm{S} / \mathrm{C}$ molar ratio between 3 and 7 and the residence time between $0.1 \mathrm{~s}^{-1}$ and $0.38 \mathrm{~s}^{-1}$. The 
results obtained were very similar to the simulated and experimental data reported by Lee et al. (2004) and Li and Cai (2007).

In order to choose a certain set of operating conditions to run the model and analyze the performance of the reactor, the equilibrium limitations of the reactions need to be taken into account. This matter has been dealt with in detail in previous works on sorption enhanced reforming, as recently reviewed by Harrison (2008) and is only briefly discussed here. The presence of a $\mathrm{CO}_{2}$ sorbent in a steam methane reforming process shifts the equilibrium to the formation of $\mathrm{H}_{2}$ with the result that an almost complete conversion of methane can be achieved. For example, if a SER operation is performed at $1.5 \mathrm{MPa}$ and around $923 \mathrm{~K}$ with a steam/carbon molar ratio of 5 in the feed, it is possible to obtain a gas product with a $\mathrm{H}_{2}$ content of about $97 \%$ (dry basis) (Fig. 2, right). Balasubramanian et al. (1999) achieved similar results working at these experimental conditions. It is also interesting to note that the hydrogen yield barely changes in the range of temperatures in which the carbonation occurs because of the quasi thermal neutrality of reaction (V). Although higher operating temperatures allow higher conversions of methane, the $\mathrm{CO}_{2}$ capture efficiency decreases if the process is carried out over $1023 \mathrm{~K}$, so that maximum $\mathrm{H}_{2}$ production is achieved around 923-1023 $\mathrm{K}$, depending on the operating pressure.

As can be seen in Fig. 2 (left), hydrogen production is favored at low pressures because of the increase in the number of moles in the products of reaction (V). However, the widespread interest in employing hydrogen for power generation and the high cost of $\mathrm{H}_{2}$ compression found in other industrial applications suggest that it would be more profitable to perform the SER process at high pressure (1.5-3.5 MPa) (Metz et al., 2005; Harrison, 2008). 
In view of these considerations, we carried out our study on SER at high pressure despite the unfavorable equilibrium conditions, due to the need to maximize the reactor performance per unit of cross-sectional area for any large scale $\mathrm{CO}_{2}$ capture system. These conditions are also important for the SER stage of the $\mathrm{Cu} / \mathrm{Ca}$ process (Abanades et al., 2010; Fernandez et al., 2012). To operate at high pressure, a high $\mathrm{S} / \mathrm{C}$ molar ratio must be fed into the reforming reactor in order to obtain a gas product with hydrogen purities of over $90 \%$ (dry basis) and elevated methane conversions of around $85 \%$, as can be seen in Fig. 2 (right). Moreover, high concentrations of $\mathrm{H}_{2}$ and low levels of $\mathrm{CO}$ in the product stream reduce the carbon deposition, thereby avoiding catalyst deactivation and the blockage of the reforming reactor, which are serious problems in conventional SMR (Tavares et al., 1996; Alstrup et al., 1998). However, the latent heat of water cannot be totally recovered from the steam (Stevens et al., 2005). Therefore we must consider as a reasonable trade-off running the SER reactor in the reference case at $3.5 \mathrm{MPa}$ at a $\mathrm{S} / \mathrm{C}$ ratio of 5.

The choice of reactor length and the superficial gas velocity or throughput per unit reaction area, must again be a trade-off between the gas-solid contact time requirements and the maximum allowable pressure drop along the reactor. At this preliminary design stage, we have adopted a reactor length of $7 \mathrm{~m}$ and an inlet mass flow velocity $\left(\mathrm{CH}_{4}+\right.$ steam) of $3.5 \mathrm{~kg} / \mathrm{m}^{2} \mathrm{~s}$. These allow reasonable cycle times (Fernández et al., 2012) and lead a sharp breakthrough during the SER reaction stage. In so far as particle size and bed porosity are concerned, which are important variables in Eqs. (9-13), we have chosen for the reference case $0.01 \mathrm{~m}$ and 0.5 , respectively, which are values commonly found inside the normal operating ranges in conventional steam reforming $(\mathrm{Xu}$ and Froment, 1989; Rostrup-Nielsen et al., 2002). 
Finally, in order to obtain concrete solutions for the model, it is necessary to define the composition of the material in the bed. When the reactor is designed for typical SER operations a $30 \%$ weight of Ni-based conventional steam reforming has proved to be sufficient (Balasubramanian et al., 1999; Lopez Ortiz et al., 2001) for achieving enough catalytic activity for the reforming reactions. This can of course be largely reduced by using a more active reforming catalyst with noble transition metals (Jones et al., 2008). In the case of SER in the initial stage of the $\mathrm{Cu} / \mathrm{Ca}$ looping process (Abanades et al., 2010), the right proportions of $\mathrm{Cu}$ and $\mathrm{CaO}$ need to be fulfilled and it is even more important to minimize the proportion of the catalyst (Fernandez et al., 2012), although several authors have shown that $\mathrm{Cu}$-based catalysts provide enough activity to carry out the SMR at high temperature (up to $973 \mathrm{~K}$ ) (Podbrscek et al., 2009).

A summary of the reactor characteristics and operating conditions for the reference case is provided in Table 3. These together with the physical parameters included in Table 2 and the initial and boundary conditions of Eqs. (14-15) make it possible to obtain a complete solution for the model.

\section{Dynamic behavior of the fixed bed reactor for sorption enhanced reforming}

The previous model has been designed to analyze the dynamic evolution of the molar concentrations of $\mathrm{CH}_{4}, \mathrm{H}_{2}$ and $\mathrm{CO}_{2}$ in the axial direction of an adiabatic fixed-bed reforming reactor, performing with the operating conditions outlined in Table 3 and evolving with time until the breakthrough curves appear, which is when the $\mathrm{CaO}$ sorbent in the bed has been almost completely converted. The simulation also allows the evolution of the axial temperature profiles and its impact on the reactor performance to be studied. 
Fig. 3 confirms the general trends observed in the SER reactors. As the gas stream passes through the bed, the molar concentration of $\mathrm{CH}_{4}$ (and $\mathrm{H}_{2} \mathrm{O}$ ) progressively decreases while the concentration of $\mathrm{H}_{2}$ increases via the reforming and water gas shift (WGS) reactions (reaction I to III). In the zones in which the CaO-based sorbent is active, the $\mathrm{CO}_{2}$ formed is almost completely removed via reaction IV. The high operating pressure facilitates very fast carbonation rates. As in other sorption enhanced reforming reactors, this carbonation reaction shifts the equilibrium to a higher $\mathrm{CH}_{4}$ conversion and a higher $\mathrm{H}_{2}$ yield than the maximum achieved in a conventional SMR. As the carbonation front advances, the inactive sorbent is left behind and consequently, the reactor performs there as a conventional steam reformer (with a lower conversion of $\mathrm{CH}_{4}$, a lower $\mathrm{H}_{2}$ yield and with no $\mathrm{CO}_{2}$ capture).

As for the evolution of the axial temperature profiles (Fig. 3, bottom right), the temperature near the reactor entrance initially drops to about $868 \mathrm{~K}$ from the initial 923 $\mathrm{K}$. This is because the highly endothermic reforming reactions (I) and (II) are faster than the exothermic $\mathrm{CaO}$ carbonation reaction (IV), resulting in a considerable drop in the temperature in the initial part of the reactor. When the gases reach the area with active $\mathrm{CaO}$, the heat supplied by the carbonation reaction makes the overall reaction slightly exothermic and the heat is transported downstream, heating the solids up to slightly above the initial temperature of $923 \mathrm{~K}$. In this way, the carbonation front raises the temperature of the bed as it moves towards the reactor exit.

The SER operation can be divided into three periods according to the evolution of the outlet temperature and gas composition with time (Fig. 4). During the prebreakthrough period $(\mathrm{t}<720 \mathrm{~s})$, the reforming, WGS and $\mathrm{CaO}$ carbonation reactions take place simultaneously and the composition of the product gas is close to the SER equilibrium (i. e. a $\mathrm{H}_{2}$ mole percent of above $94 \%$ and a content of $\mathrm{CO}_{2}$ of about $0.1 \%$ 
on a dry basis). During the breakthrough period, which takes place approximately from $\mathrm{t}=720 \mathrm{~s}$ to $\mathrm{t}=1500 \mathrm{~s}$, the $\mathrm{CO}_{2}$ capture efficiency begins to diminish because the $\mathrm{CaO}-$ sorbent is approaching its point of maximum conversion $\left(\mathrm{X}_{\max }\right)$. The extent of the reforming and the WGS reactions is gradually reduced, resulting in a decrease in hydrogen purity and in methane conversion. When all the sorbent is saturated with $\mathrm{CO}_{2}$ $(t>1500 \mathrm{~s})$, the separation is no longer effective and only the reforming and shift reactions occur. In the postbreakthrough period the bed performs as a stationary reforming reactor producing a gas stream close to the SMR equilibrium, as illustrated in Fig. $4\left(53 \%\right.$ of $\mathrm{H}_{2}, 33 \%$ of $\mathrm{CH}_{4}, 13 \%$ of $\mathrm{CO}_{2}$ and $1 \%$ of $\mathrm{CO}$ on a dry basis).

Because of the slight exothermicity of the overall reforming and carbonation reaction (reaction V), the exit gas gradually increases its temperature during the prebreakthrough period. At the beginning of the breakthrough (about $\mathrm{t}=720-900 \mathrm{~s}$ ) the maximum temperature reached is $955 \mathrm{~K}$ which represents a rise of $32 \mathrm{~K}$ above the feed gas temperature, as shown in Fig. 4 (right).

So far, the SER performance has been theoretically designed and experimentally implemented to function close to isothermal conditions (Harrison, 2008). This configuration has possibly been inherited from conventional SMR operation, in which a large amount of external heat must be supplied to the reformer in order to achieve the temperature that allows the endothermic steam reforming reaction to take place. However, only adiabatic conditions would make it possible to take full advantage of the SER thermal neutrality and maximize the energy efficiency of the process thereby eliminating the need for heat transfer equipment around the reactor. To investigate the difference between the two performances, we introduced into our model Eq. (16) for the simulation of the operation under non-adiabatic (quasi-isothermal) conditions $\left(\mathrm{T}_{\mathrm{w}}=923\right.$ 
K), similar to previous works (Lee et al., 2004; Li and Cai, 2007), but taking into account common operating parameters shown in Table 3.

As can be seen in Fig. 5, during the prebreakthrough period $(\mathrm{t}<720 \mathrm{~s})$, there is a substantial difference in the temperature of the flue gas in both configurations. However, this does not translate into any difference in hydrogen yield or methane conversion and the resulting composition of the product gas is almost the same. During the breakthrough period, the $\mathrm{CaO}$-based sorbent is approaching its point of maximum conversion and the $\mathrm{CO}_{2}$ capture efficiency begins to decay. Therefore, the proportion of $\mathrm{CO}_{2}$ in the flue gas gradually increases. At the beginning of the breakthrough (from $\mathrm{t}=720 \mathrm{~s}$ to $\mathrm{t}=1080 \mathrm{~s}$ ), the temperature of the product gas under adiabatic conditions is higher than that obtained under quasi-isothermal conditions (Fig. 5, right). Higher temperatures during this transient period from SER to SMR lead to a higher $\mathrm{CO}_{2}$ yield. Therefore, the carbonation rate increases, (Eq. 6), and the $\mathrm{CaO}$ sorbent rapidly approaches its total saturation point, resulting in a shorter breakthrough period under adiabatic conditions. These results confirm that the adiabatic configuration provides the most favorable performance for carring out the sorption enhanced reforming in fixed beds under alternative reaction conditions.

On the other hand, breakthroughs are expected to occur at well defined points of time and close to those achieved considering infinite reactions rates (dotted vertical line in Fig. 4). However, it is clear that, in order to obtain a hydrogen product gas of high purity, it is necessary to choose a point in time before the end of the breakthrough, because during this period a significant part of the $\mathrm{CaO}$-sorbent has still not been converted. Consequently, the duration of the SER stage will be a trade-off that leads to the production of a high level of $\mathrm{H}_{2}$ with a minimum loss of $\mathrm{CH}_{4}$ and $\mathrm{CO}$ and a high degree of carbonation of the $\mathrm{CaO}$-sorbent. In order to clarify this point, we must 
consider the sensitivity of the model predictions of the breakthrough curves to certain critical material properties that may affect the reactivity of $\mathrm{CaO}$ and its absorption capacity.

The sorption capacity and reactivity of the $\mathrm{CaO}$-based material may play a decisive role in the overall efficiency and viability of any process based on the SER principle. The proportion of any solids other than the active $\mathrm{CaO}$ in the fixed bed must be kept to a minimum in order to reduce the heat required for the endothermic sorbent regeneration. This is even more important in the case of the $\mathrm{Ca} / \mathrm{Cu}$ looping process (Abanades et al., 2010), where all the heat required for the calcination of the sorbent must be supplied by the reduction of a certain amount of $\mathrm{CuO}$, which is accompanied in the matrix bed by $\mathrm{CaO}$ and a reforming catalyst (Fernández et al., 2012).

As for the kinetics of carbonation, a higher sorbent capacity, expressed in terms of maximum carbonation conversion $\left(\mathrm{X}_{\max }\right)$, tends to accelerate the removal of $\mathrm{CO}_{2}$ in the SER, as shown in Eq. (6). Natural limestone can achieve a stable $\mathrm{X}_{\max }$ (after hundreds of cycles of absorption and desorption) of less than 0.10 (Grasa and Abanades, 2006) which would correspond to a sorbent capacity of about only $1 \mathrm{~mol} \mathrm{CO}_{2} / \mathrm{kg}$ sorbent. On the other hand, some novel synthetic $\mathrm{CO}_{2}$-sorbents have sorbent capacities of about 5 mol $\mathrm{CO}_{2} / \mathrm{kg}$, as reported in the literature (Ochoa et al., 2005; Manovic et al., 2009; Halabi et al., 2011). Several works in the literature dealing with CaO-based synthetic sorbents for SER or similar applications report that these sorbents maintain a high residual activity (higher than $0.3 \mathrm{~mol}$ fraction) even after a large number of carbonation/calcinations cycles (Stevens et al., 2007; Manovic and Anthony, 2008; Manovic and Anthony, 2009; Blamey et al., 2010). 
The profiles of the product gas composition on a dry basis at different maximum carbonation conversions $\left(\mathrm{X}_{\max }\right)$ are represented in Fig. 6. A hydrogen purity of close to equilibrium (95\% on a dry basis) can be achieved with sorbents with high residual activity $\left(\mathrm{X}_{\max }\right.$ higher than 0.2$)$. However, less active sorbents lead to lower $\mathrm{H}_{2}$ yields and shorter reactor operational times before the breakthrough. For this reason, natural limestones can be ruled out as sorbent candidates for this process. The prebreakthrough period can be extended from $600 \mathrm{~s}$ to $1200 \mathrm{~s}$ by using sorbents with a maximum carbonation conversion of between 0.2 and 0.4 .

The carbonation rate corresponding to two sorbents with different maximum carbonation conversions at different reformer locations is represented in Fig. 7. The sorption waves moving on along the fixed-bed demonstrate that the carbonation reaction takes place in a narrow reaction front as the feeding gas is introduced and the $\mathrm{CO}_{2}$ sorbent is saturated. The sorbent with the higher sorption capacity significantly improves the carbonation kinetics, accelerating the carbonation rate $\left(\mathrm{r}_{\text {carb }}\right)$ by a factor of 2.5. The maximum local carbonation rate achieved with the natural sorbent $\left(\mathrm{X}_{\max }=0.1\right)$ was found to be $5.5510^{-6} \mathrm{kmol} / \mathrm{kg} \mathrm{s}$, while with the synthetic sorbent $\left(\mathrm{X}_{\max }=0.4\right) \mathrm{a}$ carbonation rate of about $1.2510^{-5} \mathrm{kmol} / \mathrm{kg} \mathrm{s}$ was achieved. Moreover, Fig. 7 shows that the stationary SER period before the saturation of the bed can be extended considerably by employing materials with a higher sorption capacity, as indicated above.

On the other hand, it is well known that the initial stage of the carbonation reaction is rapid and kinetically controlled, and that it is then followed by a subsequent stage which is much slower and controlled by the diffusion of $\mathrm{CO}_{2}$ in the product layer (Bhatia and Perlmutter, 1983). According to Eq. (6), the velocity of the initial carbonation stage is mainly determined by the carbonation rate constant $\left(\mathrm{k}_{\mathrm{carb}}\right)$. As pointed out above, natural 
limestones present values of $\mathrm{k}_{\text {carb }}$ of around $0.35 \mathrm{~s}^{-1}$. It is possible to find in the literature several works that employ synthetic $\mathrm{CO}_{2}$ sorbents with a higher mechanical and chemical stability but with less reactivity (lower $\mathrm{k}_{\text {carb }}$ ) (Lee et al., 2004; Li and Cai, 2007). Nevertheless, there are also many works that have attempted to obtain sorbents with a better stability and reactivity than natural sorbents by using new synthesis routes (Stevens et al., 2007; Blamey et al., 2010) or recently developed materials that combine both sorbent and catalyst properties (Martavaltzi et al, 2010; Meyer et al., 2011).

The effect of the carbonation rate constant $\left(\mathrm{k}_{\mathrm{carb}}\right)$ on the evolution of the outlet gas composition and temperature with time is represented in Fig. 8, under conditions of 923 $\mathrm{K}, 3.5 \mathrm{MPa}$, by feeding $3.5 \mathrm{~kg} / \mathrm{m}^{2} \mathrm{~s}$ with a $\mathrm{S} / \mathrm{C}$ molar ratio of 5 and assuming a maximum carbonation conversion for the sorbent $\left(\mathrm{X}_{\max }\right)$ of 0.4 . As can be seen in Fig. 8 , a less reactive sorbent with half the reactivity of a natural limestone $\left(\mathrm{k}_{\mathrm{carb}}=0.18 \mathrm{~s}^{-1}\right)$ does not allow the SER equilibrium (97\% on a dry basis) to be reached and therefore a lower degree of hydrogen purity is obtained ( $92 \%$ on a dry basis). Moreover, less reactive sorbents do not lead to sharp breakthroughs, which involve shorter cycles during the SER operation if the objective is to obtain a gas product with high $\mathrm{H}_{2}$ purity and a minimum loss of $\mathrm{CH}_{4}$ and $\mathrm{CO}$.

However, natural limestones and more reactive sorbents $\left(\mathrm{k}_{\mathrm{carb}}>0.35 \mathrm{~s}^{-1}\right)$ allow a SER performance close to equilibrium and a maximum $\mathrm{H}_{2}$ content of about $97 \%$ is therefore obtained. Hypothetical more reactive sorbents than natural limestones would allow sharper breakthroughs to be reached, but the resulting stationary period (prebreakthrough) would not be much longer. As pointed out above, the prebreakthrough period with a natural limestone as $\mathrm{CO}_{2}$ sorbent takes place during the first $720 \mathrm{~s}$ of the SER performance under the operating conditions listed in Table 3 . The 
use of a hypothetical sorbent 10 times more reactive $\left(k_{c a r b}=3.5 \mathrm{~s}^{-1}\right)$ only extends the prebreakthrough period from $720 \mathrm{~s}$ to $900 \mathrm{~s}$, as shown in Fig. 8 (left).

As for the temperature profiles of the flue gas, these are more affected by the carbonation rate constant. If the carbonation reaction is very slow, this exothermic reaction takes place gradually along the fixed bed, while the rapid endothermic reforming reaction occurs in a narrow front. The result is a slight increase in the flue gas temperature during the SER operation. If the sorbent is highly reactive leading to a much faster $\mathrm{CO}_{2}$ absorption, all the reactions involved in the SER process take place simultaneously in the same reaction fronts along the fixed-bed, with the result that the maximum temperature achieved increases, as can be seen in Fig. 8 (right). If a slowreacting sorbent is used $\left(\mathrm{k}_{\mathrm{carb}}=0.18 \mathrm{~s}^{-1}\right)$, the maximum temperature achieved during the SER operation is $943 \mathrm{~K}$, whereas $\mathrm{T}_{\max }$ increases up to $990 \mathrm{~K}$ if an extremely high reactive sorbent $\left(\mathrm{k}_{\mathrm{carb}}=3.5 \mathrm{~s}^{-1}, 10\right.$ times greater than the carbonation constant for a natural $\mathrm{CO}_{2}$-sorbent) is used since this entails practically instantaneous carbonation. This value is close to $1006 \mathrm{~K}$, which is the maximum temperature theoretically estimated for an adiabatic SER process, if instantaneous kinetics are considered (Fernández et al., 2012). Furthermore, the minimum temperature reached during the postbreakthrough period is not affected by the carbonation kinetics. In either case, the saturated bed cools down to a stationary temperature of about $868 \mathrm{~K}$.

The carbonation rate $\left(\mathrm{r}_{\text {carb }}\right)$ for two $\mathrm{CO}_{2}$ sorbents of different reactivity (a natural limestone and a hypothetical synthetic sorbent 10 times more reactive) in different reformer locations is represented in Fig. 9. The results show that a higher carbonation rate constant $\left(\mathrm{k}_{\mathrm{carb}}\right)$ significantly improves the carbonation kinetics. The maximum local carbonation rate with the natural limestone $\left(\mathrm{k}_{\mathrm{carb}}=0.35 \mathrm{~s}^{-1}\right)$ was found to be around 1.4 
$10^{-5} \mathrm{kmol} / \mathrm{kg} \mathrm{s}$, while the synthetic sorbent $\left(\mathrm{k}_{\mathrm{carb}}=3.5 \mathrm{~s}^{-1}\right)$ attained a carbonation rate higher than $1.1110^{-4} \mathrm{kmol} / \mathrm{kg} \mathrm{s}$. A great increase in the reactivity of the sorbent leads to very narrow carbonation reaction fronts. However, the use of very reactive sorbents does not involve higher velocities of the carbonation reaction front along the fixed-bed. Fig. 9 shows that both sorbents exhibit their maximum local carbonation rate for every axial location at similar operating times. Therefore, efforts to develop more reactive synthetic $\mathrm{CO}_{2}$ sorbents would only lead to shorter breakthroughs with similar stationary SER periods before bed saturation.

As explained above, sorbents with a higher reactivity accelerate the removal of $\mathrm{CO}_{2}$ in the SER and therefore it is possible to perform close to equilibrium at higher space velocities. Fig. 10 shows the composition and temperature profiles of the product gas on a dry basis at different space velocities $\left(2.1,3.5\right.$ and $\left.7 \mathrm{~kg} / \mathrm{m}^{2} \mathrm{~s}\right)$ for sorbents with a different carbonation rate constant $\left(0.18,0.35\right.$ and $\left.0.70 \mathrm{~s}^{-1}\right)$, at $923 \mathrm{~K}, 3.5 \mathrm{MPa}$ and a $\mathrm{S} / \mathrm{C}$ molar ratio of 5 . Under these operating conditions, the maximum superficial velocity reached by the gas in the reforming reactor would be $0.3,0.5$ and $1 \mathrm{~m} / \mathrm{s}$, respectively.

Slow-reacting $\mathrm{CO}_{2}$ sorbents do not allow the maximum hydrogen purity determined by the equilibrium at elevated space velocities to be achieved. Higher residence times are therefore needed. These will require longer operational periods to permit total sorbent saturation and entail higher capital investment and operating costs. However, highly reactive materials lead to a maximum hydrogen production at higher space velocities, which in turn entails shorter SER cycles for total sorbent carbonation.

As indicated in Fig. 10, a $\mathrm{CO}_{2}$ sorbent with slow carbonation kinetics $\left(\mathrm{k}_{\mathrm{carb}}=0.18 \mathrm{~s}^{-1}\right)$ requires low space velocities $\left(2.1 \mathrm{~kg} / \mathrm{m}^{2} \mathrm{~s}\right)$ in order to achieve the maximum degree of 
$\mathrm{H}_{2}$ purity determined by the SER equilibrium (95\% on a dry basis). Under these operating conditions, the postbreakthrough period is finally achieved after $2700 \mathrm{~s}$ of performance. If a sorbent with a significantly higher carbonation rate is used $\left(\mathrm{k}_{\mathrm{carb}}=0.70\right.$ $\mathrm{s}^{-1}$, twice the carbonation rate constant of a natural $\mathrm{CO}_{2}$-sorbent), the SER operation can be carried out at a space velocity of about $7 \mathrm{~kg} / \mathrm{m}^{2} \mathrm{~s}$ (around $1 \mathrm{~m} / \mathrm{s}$ under these operating conditions) which corresponds approximately to velocities usually employed in conventional steam reformers at industrial scale (Rostrup-Nielsen et al., 2002). Moreover, the duration of the cycle up to total sorbent saturation can be reduced from $2700 \mathrm{~s}$ to $780 \mathrm{~s}$. Neither the maximum temperature reached in the SER operation ( 953 $\mathrm{K})$ nor the minimum temperature in the postsbreakthrough period $(868 \mathrm{~K})$ are affected by the use of the maximum allowable space velocity for achieving equilibrium according to the carbonation kinetics of the sorbent, as can be seen in Fig. 10.

The above analysis highlights the importance of $\mathrm{CaO}$ reactivity (fast reaction rate) and the carrying capacity of synthetic $\mathrm{CO}_{2}$ sorbents for SER applications. In order to be able to design compact reactors that optimize the production of hydrogen with sharp breakthroughs, it is essential to employ materials with maximum carbonation conversions $\left(\mathrm{X}_{\max }\right)$ of at least 0.4 (about 3-4 times higher than natural sorbents) and with a carbonation rate constant $\left(\mathrm{k}_{\text {carb }}\right)$ at least similar to those measured in natural limestones. There are two major ways to achieve this condition: (i) to design stable materials with the appropriate properties (high $\mathrm{X}_{\max }$ or high $\mathrm{k}_{\mathrm{carb}}$ ) or (ii) to design intermediate steps for sorbent reactivation. Promising results have been recently published in both directions (see review of Blamey et al., 2010), stimulating a huge amount of interest in the use of $\mathrm{CaO}$-based sorbents in the sorption enhanced reforming process. 


\section{Conclusions}

Adiabatic sorption-enhanced steam reforming (SER) reactors using $\mathrm{CaO}$ as a $\mathrm{CO}_{2}$ sorbent can be mathematically described using well established principles for fixed-bed reactors. The resulting pseudo-homogeneous model is able to describe the transient behaviour of the SER process from a set of initial conditions to a point beyond the breakthrough associated to the full conversion of the $\mathrm{CaO}$. Three different periods have been established: (i) prebreakthrough, in which the reactor can perform close to the SER equilibrium in which case the hydrogen yield is maximum and the $\mathrm{CO}_{2}$ production is negligible; (ii) breakthrough in which $\mathrm{CO}_{2}$ capture efficiency decays because the sorbent is approaching its maximum limit of conversion, and (iii) postbreakthrough in which the $\mathrm{CO}_{2}$-sorbent reaches total saturation and consequently the reactor performs like a conventional steam methane reformer. The process was found to be highly efficient at $923 \mathrm{~K}, 3.5 \mathrm{MPa}$, feeding a S/C molar ratio of 5 and at a space velocity of 3.5 $\mathrm{kg} / \mathrm{m}^{2}$ s, yielding a hydrogen purity of about $95 \%$, a methane conversion of about $85 \%$ and negligible traces of $\mathrm{CO}_{2}$. The limiting aspect of the SER process was found to be basically the carbonation kinetics, making it necessary to use lower space velocities than those employed in the conventional steam reforming (SMR). Natural limestones can be ruled out as $\mathrm{CaO}$ precursors for this process. $\mathrm{CO}_{2}$-sorbents with a high sorption capacity are more suitable because they permit faster carbonation kinetics and a longer operational time before the breakthrough.

\section{Acknowledgements}

The authors acknowledge the grant awarded by the Spanish Science and Innovation Ministry under the project ENE2009-11353 and CSIC (201280E017). 


\section{Nomenclature}

$\mathrm{C}_{\mathrm{i}} \quad$ concentration of component $\mathrm{i}$ in the reactor, $\mathrm{kmol} / \mathrm{m}^{3}$

$\mathrm{C}_{\mathrm{i}, \text { in }} \quad$ concentration of component $\mathrm{i}$ in the feed, $\mathrm{kmol} / \mathrm{m}^{3}$

$\mathrm{C}_{\mathrm{i}, 0} \quad$ initial concentration of component $\mathrm{i}, \mathrm{kmol} / \mathrm{m}^{3}$

$\mathrm{C}_{\mathrm{pg}} \quad$ specific heat capacity of the gas, $\mathrm{kJ} / \mathrm{kg} \mathrm{K}$

$\mathrm{C}_{\mathrm{ps}} \quad$ specific heat capacity of the solid, $\mathrm{kJ} / \mathrm{kg} \mathrm{K}$

$D_{e} \quad$ effective diffusivity, $\mathrm{m}^{2} / \mathrm{s}$

$d_{p} \quad$ particle diameter, $m$

$\mathrm{D}_{\mathrm{r}} \quad$ inner diameter of the reactor, $\mathrm{m}$

$\mathrm{H}_{\text {carb }} \quad$ heat of $\mathrm{CaO}$ carbonation, $\mathrm{kJ} / \mathrm{kmol}$

$\mathrm{h}_{\mathrm{fs}} \quad$ fluid-gas heat transfer coefficient, $\mathrm{kW} /\left(\mathrm{m}^{2} \mathrm{~K}\right)$

$\mathrm{H}_{\mathrm{Rj}} \quad$ heat of reaction $\mathrm{j}(\mathrm{j}=\mathrm{I}, \mathrm{II}, \mathrm{III}), \mathrm{kJ} / \mathrm{kmol}$

$\mathrm{h}_{\mathrm{w}} \quad$ heat transfer coefficient through the reactor wall, $\mathrm{kW} /\left(\mathrm{m}^{2} \mathrm{~K}\right)$

$\mathrm{k}_{\text {carb }} \quad$ rate constant of $\mathrm{CaO}$ carbonation, $\mathrm{s}^{-1}$

$\mathrm{k}_{\mathrm{g}} \quad$ thermal gas conductivity, $\mathrm{kW} /(\mathrm{mK})$

$\mathrm{k}_{\mathrm{j}} \quad$ rate constant of reaction $\mathrm{j}(\mathrm{j}=\mathrm{I}, \mathrm{II}, \mathrm{III}), \mathrm{kmol} \mathrm{MPa}^{0.5} / \mathrm{kg} \mathrm{s}$

$\mathrm{K}_{\mathrm{i}}$ adsorption constant of component i, i=CO, $\mathrm{H}_{2}, \mathrm{CH}_{4} \quad \mathrm{MPa}^{-1} ; \mathrm{i}=\mathrm{H}_{2} \mathrm{O}$ dimensionless

$\mathrm{K}_{\mathrm{j}} \quad$ equilibrium constant of reaction $\mathrm{j}, \mathrm{j}=\mathrm{I}$, II $\mathrm{MPa}^{2} ; \mathrm{j}=3$ dimensionless

$\mathrm{k}_{\mathrm{fs}} \quad$ gas-solid mass transfer coefficient, $\mathrm{m} / \mathrm{s}$

$\mathrm{L} \quad$ reactor length, $\mathrm{m}$

$\mathrm{M}_{\mathrm{CaO}}$ molecular weight of $\mathrm{CaO}, \mathrm{kg} / \mathrm{kmol}$

$\mathrm{M}_{\mathrm{g}} \quad$ molecular weight of the gas, $\mathrm{kg} / \mathrm{kmol}$

$\mathrm{P} \quad$ total pressure, $\mathrm{MPa}$ 
$\mathrm{P}_{\mathrm{i}} \quad$ partial pressure of component $\mathrm{i}, \mathrm{MPa}$

$\mathrm{P}_{\text {in }} \quad$ pressure at the reactor entrance, $\mathrm{MPa}$

$\mathrm{r}_{\text {carb }} \quad$ rate of $\mathrm{CaO}$ carbonation, $\mathrm{kmol} / \mathrm{kg}_{\text {cat }} \mathrm{S}$

$r_{i} \quad$ rate of formation/consumption of component $\mathrm{i}, \mathrm{kmol} / \mathrm{kg} \mathrm{s}$

$\mathrm{R} \quad$ ideal gas constant, $\mathrm{kJ} / \mathrm{kmol} \mathrm{K}$

$R_{j} \quad$ rate of reaction $\mathrm{j}(\mathrm{j}=\mathrm{I}, \mathrm{II}, \mathrm{III}), \mathrm{kmol} / \mathrm{kg} \mathrm{s}$

t time, $s$

$\mathrm{T} \quad$ temperature, $\mathrm{K}$

$\mathrm{T}_{\mathrm{w}} \quad$ reactor wall temperature, $\mathrm{K}$

$\mathrm{T}_{\text {in }} \quad$ feed gas temperature, $\mathrm{K}$

$\mathrm{T}_{0} \quad$ initial temperature of the solids in the reactor, $\mathrm{K}$

$\mathrm{u} \quad$ superficial velocity of gas, $\mathrm{m} / \mathrm{s}$

$\mathrm{x}_{\mathrm{i}}$ gas-phase mole fraction of component $\mathrm{i}$, dimensionless

$\mathrm{X}$ fractional carbonation conversion of $\mathrm{CaO}$, dimensionless

$\mathrm{X}_{\max }$ maximum fractional carbonation conversion of $\mathrm{CaO}$, dimensionless

$\mathrm{z} \quad$ axial coordinate in bed, $\mathrm{m}$

Greek letters

$\varepsilon \quad$ bed void fraction, dimensionless

$\varphi_{\mathrm{ij}} \quad$ stoichiometric coefficient of component $\mathrm{i}$, dimensionless

$\rho_{\mathrm{CaO}} \quad$ apparent density of $\mathrm{CaO}$-based material, $\mathrm{kg} / \mathrm{m}^{3}$

$\rho_{\text {cat }} \quad$ apparent density of reforming catalyst, $\mathrm{kg} / \mathrm{m}^{3}$

$\rho_{\mathrm{g}} \quad$ gas phase density, $\mathrm{kg} / \mathrm{m}^{3}$

$\rho_{\mathrm{s}} \quad$ apparent density of the two mixed solids in the reactor, $\mathrm{kg} / \mathrm{m}^{3}$

$\eta \quad$ effectiveness factor, dimensionless 
$v_{\mathrm{CO} 2}$ gas-phase mole fraction of $\mathrm{CO}_{2}$, dimensionless

$v_{\mathrm{CO} 2 \text {,eq }}$ gas-phase equilibrium mole fraction of $\mathrm{CO}_{2}$, dimensionless

$\mu_{\mathrm{g}} \quad$ viscosity of gas, MPa s

\section{References}

Abanades, J. C., 2002. The maximum capture efficiency of CO2 using a carbonation/calcinations cycle of $\mathrm{CaO} / \mathrm{CaCO}_{3}$. Chemical Engineering Journal 90, 303-306.

Abanades, J. C., Murillo, R., Fernandez, J.R.; Grasa, G., Martinez, I., 2010. New $\mathrm{CO}_{2}$ capture Process for Hydrogen production Combining $\mathrm{Ca}$ and $\mathrm{Cu}$ Chemical Loops. Environmental Science \& Technology 44, 6901-6904.

Alstrup, I., Tavares, M. T., Bernardo, C. A., Sorensen, O., Rostrup-Nielsen, J. R., 1998. Carbon formation on nickel and nickel-copper allow catalyst. Materials and Corrosion 49, 367-372.

Balasubramanian, B., Lopez Ortiz, A., Kaytakoglu, S., Harrison, D.P., 1999. Hydrogen from methane in a single-step process. Chemical Engineering Science 54, 35433552.

Baker, E. H. 1962. The calcium oxide-calcium dioxide system in the pressure range 1300 atmospheres. Journal of the Chemical Society 464-470.

Blamey, J., Anthony, E. J., Wang, J., Fennell, P. S., 2010. The calcium looping cycle for large-scale $\mathrm{CO}_{2}$ capture. Progress in Energy and Combustion Science 36 (2), 260-279. 
Bhatia, S. K., Perlmutter, D. D. 1983. Effect of the product layer on the kinetics of the $\mathrm{CO}_{2}$-lime reaction. AIChe Journal 29, 79-86.

Borman, P. C., Borkink, J. G. H., Westerterp, K. R., 1992. Heat transport in a wall heated tubular packed bed reactor at elevated pressures and temperatures. Chemical Engineering Communications 114, 17-47.

Breault, W. B. 2006. A review of gas-solid dispersion and mass transfer coefficient correlations in circulating fluidized beds. Powder Technology 163, 9-17.

Dennis, J. S., Hayhurst, A. N. 1987. The effect of $\mathrm{CO}_{2}$ on the kinetics and extent of calcinations of limestone and dolomite particles in fluidized beds. Chemical Engineering Science 42, 2361-2372.

Dixon, A. D., 1979. Theoretical prediction of effective heat transfer parameters in packed beds. AIChE Journal 25, 663-676.

Dybkjaer, I., 1995. Tubular reforming and autothermal reforming of natural gas -an overview of available processes. Fuel Processing Technology 42, 85-107.

Ergun, S. 1952. Fluid flow through packed columns. Chemical Engineering Progress 48, 89-94.

Fernández, J.R.; Abanades, J. C., Murillo, R., Grasa, G., 2012. Conceptual design of a hydrogen production process from natural gas with $\mathrm{CO}_{2}$ capture using a $\mathrm{Ca}-\mathrm{Cu}$ chemical loop. International Journal of Greenhouse Gas Control, 6, 126-141.

Florin, N. H.; Harris, A. T., 2008. Enhanced hydrogen production from biomass with in situ carbon dioxide capture using calcium oxide sorbents. Chemical Engineering Science 63, 287-316. 
Grasa, G., Abanades, J. C. 2006. Capture Capacity of $\mathrm{CaO}$ in Long Series of Carbonation/Calcination cycles. Industrial \& Engineering Chemistry Research 45, $8846-8851$.

Grasa, G., Abanades, J. C., Alonso, M., González, B. 2008. Reactivity of highly cycled particles of $\mathrm{CaO}$ in a carbonation/calcinations loop. Chemical Engineering Journal $137,561-567$.

Grasa, G., Murillo, R., Alonso, M., Abanades, J. C. 2009. Application of the Random Pore Model to the Carbonation Cyclic Reaction. AIChe Journal 55, 1246-1255.

Grasa, G., Abanades, J. C., Alonso, M., González, B. 2008. Reactivity of highly cycled particles of $\mathrm{CaO}$ in a carbonation/calcinations loop. Chemical Engineering Journal $137,561-567$.

Halabi, M. H., de Croon, M. H. J. M., van der Schaaf, J., Cobden, P. D., Schouten, J. C. 2011. Reactor modeling of sorption enhanced autothermal reforming of methane. Part I: Performance study of hydrotalcite and lithium zirconate-based process. Chemical Engineering Journal 168, 872-882.

Halabi, M. H., de Croon, M. H. J. M., van der Schaaf, J., Cobden, P. D., Schouten, J. C. 2011. Effect of operational paramenters. Part II: Performance study of hydrotalcite and lithium zirconate-based process. Chemical Engineering Journal 168, 872-882.

Harrison, D. P., 2008. Sorption-Enhanced Hydrogen Production: A Review. Industrial \& Engineering Chemistry Research 47, 6486-6501.

Hufton, J. R., Mayorga, S., Sircar, S. 1999. Sorption-enhanced reaction process for hydrogen production. AIChe Journal 45, 248-256. 
Jones, G., Jakobsen, J. G., Shim, S. S., Kleis, J., 2008. First principles calculations and experimental insight into methane steam reforming over transition metal catalysts. Journal of Catalysis 259, 147-160.

Lee, D. K., Baek, I. H., Yoon, W. L., 2004. Modeling and simulation for the methane steam reforming enhanced by in situ $\mathrm{CO}_{2}$ removal utilizing the $\mathrm{CaO}$ carbonation for $\mathrm{H}_{2}$ production. Chemical Engineering Science 59, 931-942.

Levenspiel, O. S., 1979. The Chemical Reactor Omnibook, Oregon State University Book Stores.

Li, Z., Cai, N., 2007. Modeling of Multiple Cycles for Sorption-Enhanced Steam Methane Reforming and Sorbent Regeneration in Fixed Bed Reactor. Energy \& Fuels 21, 2909-2918.

Lopez Ortiz, A., Harrison, D.P., 2001. Hydrogen Production Using Sorption-Enhanced Reaction. Industrial \& Engineering Chemistry Research 40, 5102-5109.

Lysikov, A. I., Trukhan, S. N., Okunev, A. G., 2008. Sorption enhanced hydrocarbons reforming for fuel cell powered generators. International Journal of Hydrogen Energy 33, 3061-3066.

Manovic, V., Anthony, E. J., 2008. Thermal activation of CaO-based sorbent and selfreactivation during $\mathrm{CO}_{2}$ capture looping cycles. Environmental Science \& Technology 42, 4170-4174.

Manovic, V., Anthony, E. J., 2009. Long-term behavior of CaO-based pellets supported by calcium aluminate cements in a long series of $\mathrm{CO}_{2}$ capture cycles. Industrial \& Engineering Chemistry Research 48, 8906-8912. 
Martavaltzi, C. S., Lemonidou, A. A., 2010. Hydrogen production via sorption enhanced reforming of methane: Development of a novel hybrid material-reforming catalyst and $\mathrm{CO}_{2}$ sorbent. Chemical Engineering Science 65, 4134-4140.

McCabe W. L., Smith, J. C., Harriot, P. 1985. Unit Operations in Chemical Engineering, McGraw-Hill, New York.

Meyer, J., Mastin, J., Bjornebole, T. K., Ryberg, T.; Eldrup, N., 2011. Technoeconomical study of the Zero Emission Gas power concept. Energy Procedia. 4, 1949-1956.

Metz, B., Davidson, O., de Coninck, H., Loos, M., Meyer, L., 2005. IPPC Special Report on Carbon Dioxide Capture and Storage, Intergovernmental Panel on Climate Change. Cambridge University Press.

Ochoa-Fernandez, E., Rusten, H. K., Jakobsen, H. A., Holmen, A., Chen, D., 2005. Sorption enhanced hydrogen production by steam methane reforming using $\mathrm{Li}_{2} \mathrm{ZrO}_{3}$ as sorbent: sorption kinetics and reactor simulation. Catalysis Today 106, 41-46.

Podbrscek, P., Orel, Z. C., Macek, J., 2009. Low temperature synthesis of porous copper/zinc oxide. Materials Research Bulletin 44, 1642-1646.

Reijers, H. T. J.; Boon, J., Elzinga, G. D., Cobden, P. D., Haije, W. G., van den Brink, R. W. 2009. Modeling Study of the Sorption-Enhanced Reaction Process for $\mathrm{CO}_{2}$ Capture. I. Model Development and Validation. Industrial \& Engineering Chemistry Research 48, 6966-6974 
Reijers, H. T. J.; Boon, J., Elzinga, G. D., Cobden, P. D., Haije, W. G., van den Brink, R. W. 2009. Modeling Study of the Sorption-Enhanced Reaction Process for $\mathrm{CO}_{2}$ Capture. II. Application to Steam-Methane Reforming. Industrial \& Engineering Chemistry Research 48, 6966-6974

Rodríguez, N., Alonso, M., Abanades, J. C. 2011. Experimental Investigation of a Circulating Fluidized-Bed Reactor to Capture $\mathrm{CO}_{2}$ with $\mathrm{CaO}$. AIChe Journal 57, $1356-1366$

Rostrup-Nielsen, J. R., Sehested, J., Norskov, J. K., 2002. Hydrogen and Synthesis Gas by Steam and $\mathrm{CO}_{2}$ Reforming. Advances in Catalysis 47, 65-139.

Rusten, H. K., Ochoa-Fernández, E., Chen, D., Jakobsen, H. A., 2007. Numerical Investigation of Sorption Enhanced Steam Methane Reforming Using $\mathrm{Li}_{2} \mathrm{ZrO}_{3}$ as $\mathrm{CO}_{2}$-acceptor. Industrial \& Engineering Chemistry Research 46, 4435-4443.

Solsvik, J., Jakobsen, H. A., 2011. A numerical study of a two property catalyst/sorbent pellet design for the sorption-enhanced steam-methane reforming process: Modeling complexity and parameter sensitivity study. Chemical Engineering Journal 178, 407-422.

Stevens, J. F., Krishnamurthy, B., Atanassova, P., Spilker, K., 2007. Development of 50 kW Fuel Processor for Stationary Fuel Cell Applications, Final Report, $\mathrm{DOE} / \mathrm{GO} / 13102-1$.

Tavares, M. T., Alstrup, I., Bernardo, C. A., Rostrup-Nielsen, J. R., 1996. Carbon deposition and $\mathrm{CO}$ methanation on silica-supported nickel and nickel copper catalysts in $\mathrm{CO}+\mathrm{H}_{2}$ mixtures. Journal of Catalysis $158,402-410$. 
Twigg, M. V. 1989. Catalyst Handbook, Wolfe Publishing Ltd., UK.

Xiu, G. H., Li, P., Rodrigues, A. E. 2002. Sorption-enhanced reaction process with reactive regeneration. Chemical Engineering Science 57, 3893-3908.

Xu, J., Froment, G. F., 1989. Methane steam reforming, methanation and water-gas shift: I. Intrinsic kinetics. AIChe Journal 35, 88-96.

Yi, K. B., Harrison, D. P., 2005. Low-Pressure Sorption-Enhanced Hydrogen Production. Industrial \& Engineering Chemistry Research 44, 1665-1669.

Yoon, Y. I., Baek, I. H., Park, S. D., 2007. Enhancement of $\mathrm{H}_{2}$ production by combination with $\mathrm{CO}_{2}$ absorption in steam methane reforming in bench scale. Journal of Industrial Engineering Chemistry 13 (5), 842-849. 


\section{Figure captions}

Fig. 1. General scheme of the composition and temperature profiles in the reaction front during the SER in a fixed-bed reactor.

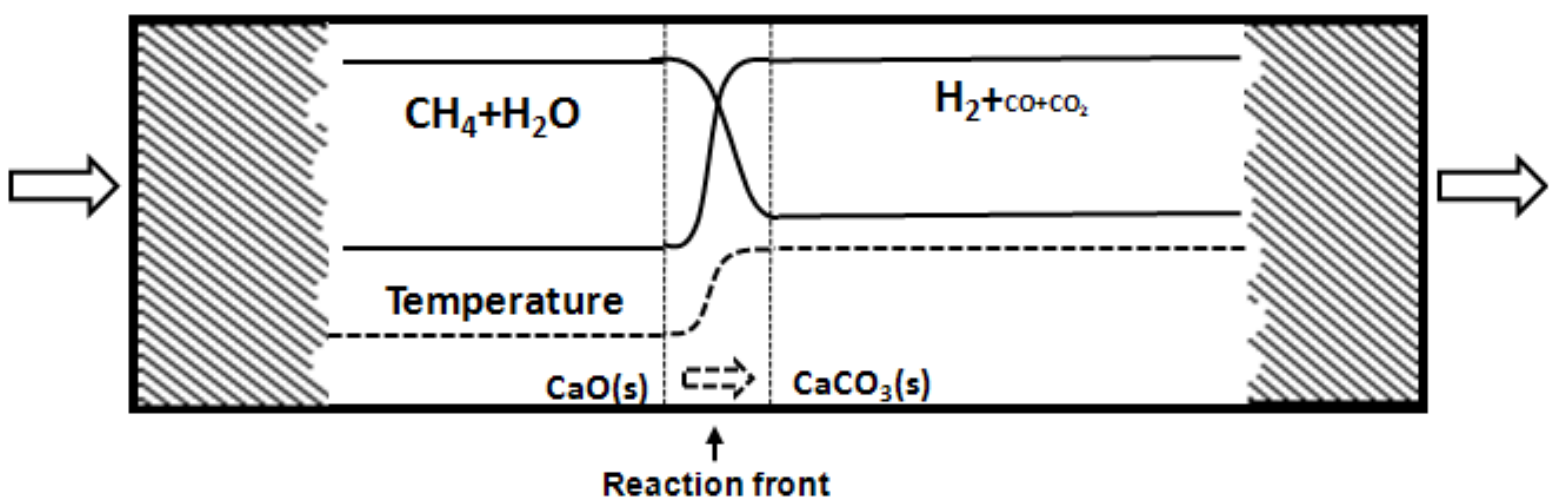


Fig. 2. Effect of pressure, temperature and S/C molar ratio in hydrogen production and methane conversion on the sorption enhanced reforming equilibriums; ( $\mathrm{S} / \mathrm{C}=5$, left and $\mathrm{P}=3.5 \mathrm{MPa}$, right).
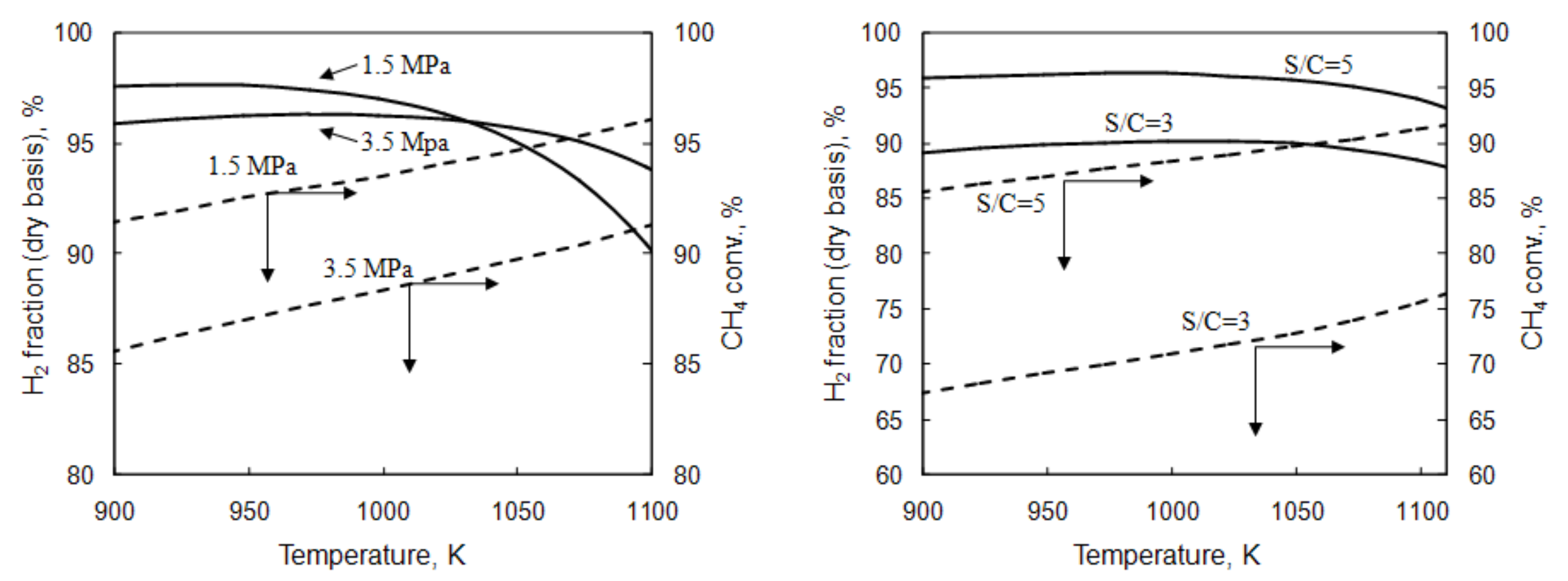
Fig. 3. Dynamic profiles of $\mathrm{CH} 4, \mathrm{H} 2, \mathrm{CO} 2$ and temperature in a SER operation carried out in an adiabatic fixed-bed reactor (at the conditions shown in Table 3: $923 \mathrm{~K}, 3.5$ $\mathrm{MPa}, \mathrm{S} / \mathrm{C}$ molar ratio of 5).
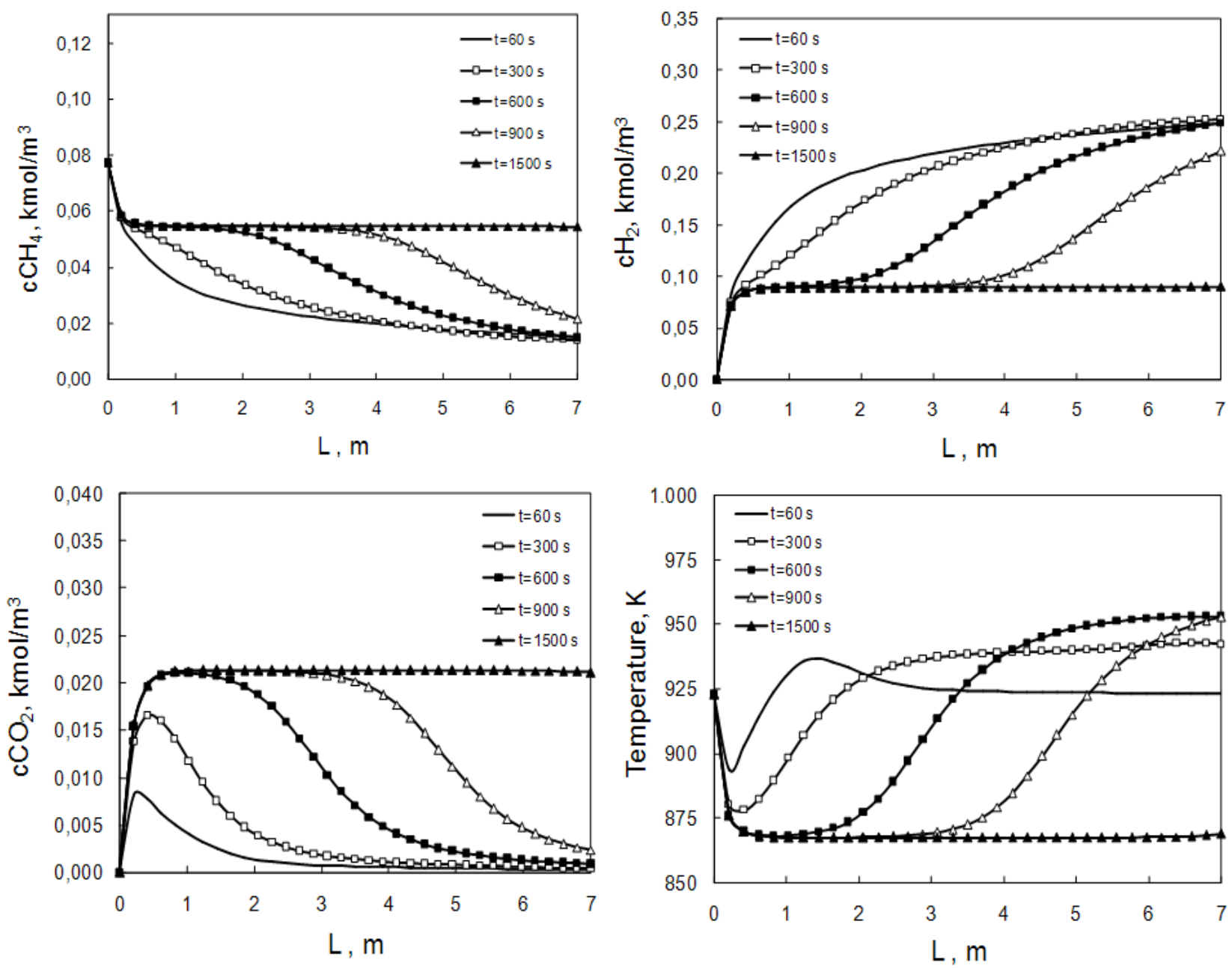
Fig. 4. Product gas composition on a dry basis and temperature evolution of the gases leaving the reactor time on stream (at the conditions shown in Table 3: $923 \mathrm{~K}, 3.5 \mathrm{MPa}, \mathrm{S} / \mathrm{C}$ molar ratio of 5).
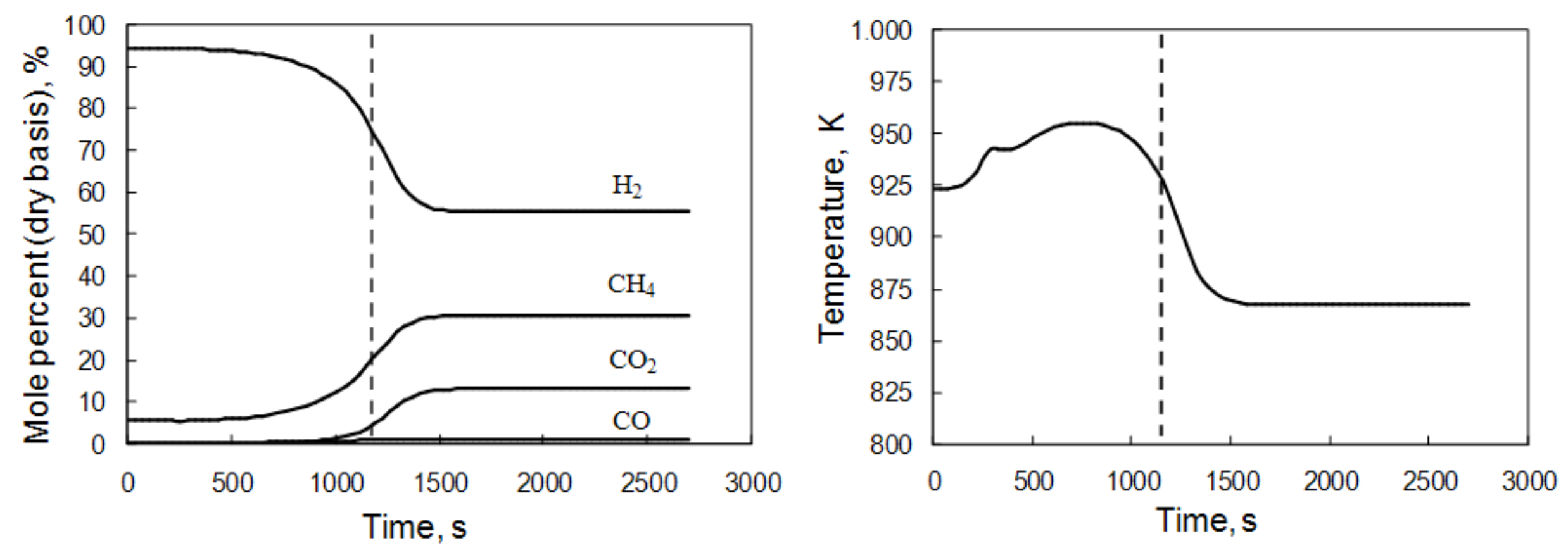
Fig. 5. Comparison of adiabatic and non-adiabatic SER performance in terms of product gas composition and temperature profiles time on stream (at the conditions shown in Table 3: $923 \mathrm{~K}, 3.5 \mathrm{MPa}, \mathrm{S} / \mathrm{C}$ molar ratio of 5).
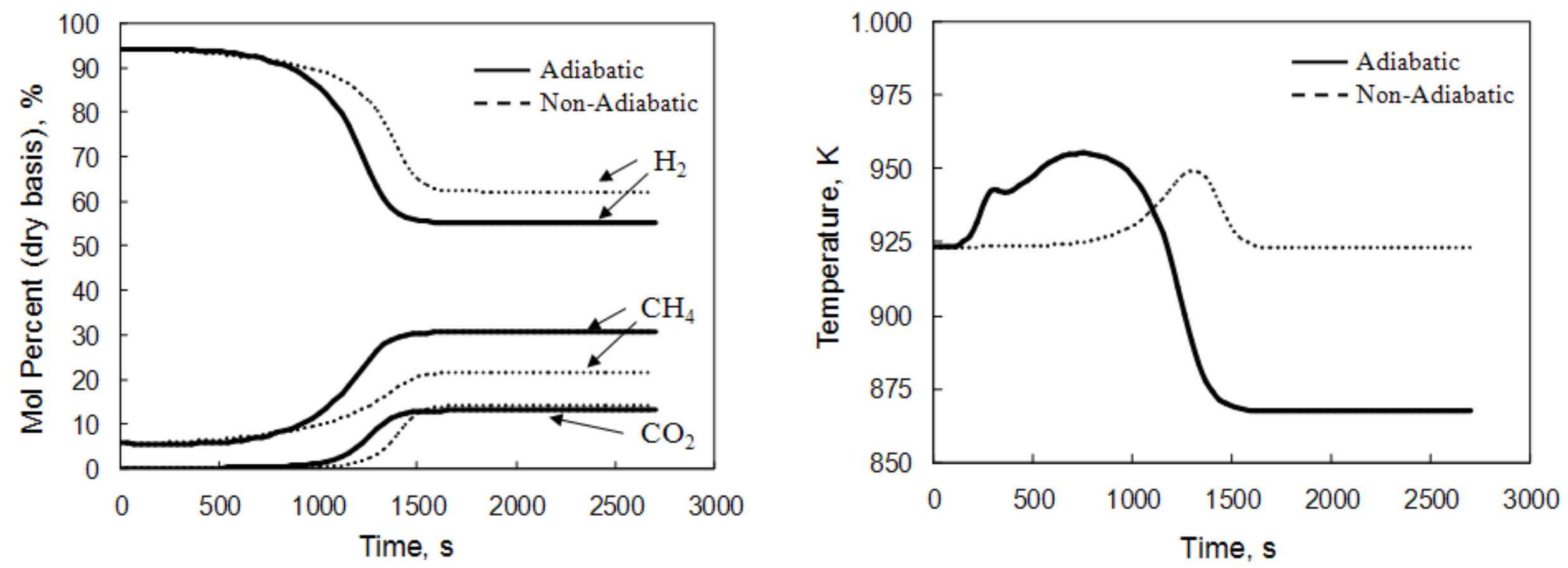
Fig. 6. Dynamic $\mathrm{H}_{2}$ and $\mathrm{CO}_{2}$ profiles on a dry basis at the reactor exit at different maximum carbonation conversions $\left(923 \mathrm{~K}, 3.5 \mathrm{MPa}, \mathrm{S} / \mathrm{C}\right.$ molar ratio of $5,2 \mathrm{~kg} / \mathrm{m}^{2} \mathrm{~s}$ and $\left.\mathrm{k}_{\mathrm{carb}}=0.35 \mathrm{~s}^{-1}\right)$.

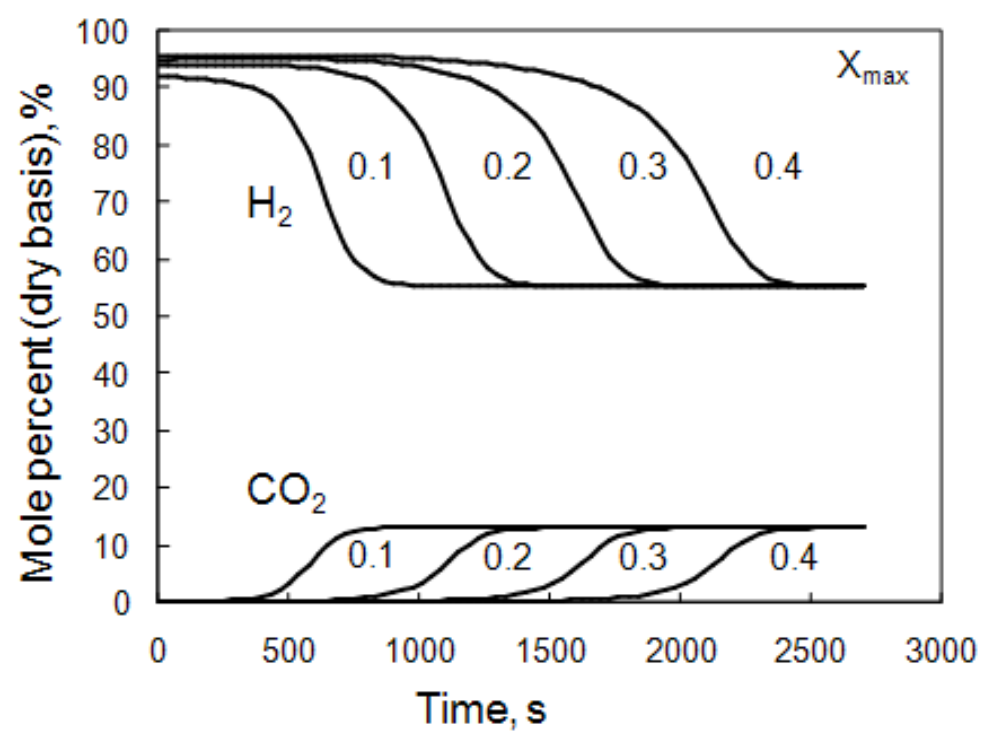

Fig. 7. Effect of maximum carbonation conversion on the carbonation rate at different locations along the reformer $\left(923 \mathrm{~K}, 3.5 \mathrm{MPa}, \mathrm{S} / \mathrm{C}\right.$ molar ratio of $5,2 \mathrm{~kg} / \mathrm{m}^{2} \mathrm{~s}$ and $\left.\mathrm{k}_{\mathrm{carb}}=0.35 \mathrm{~s}^{-1}\right)$.

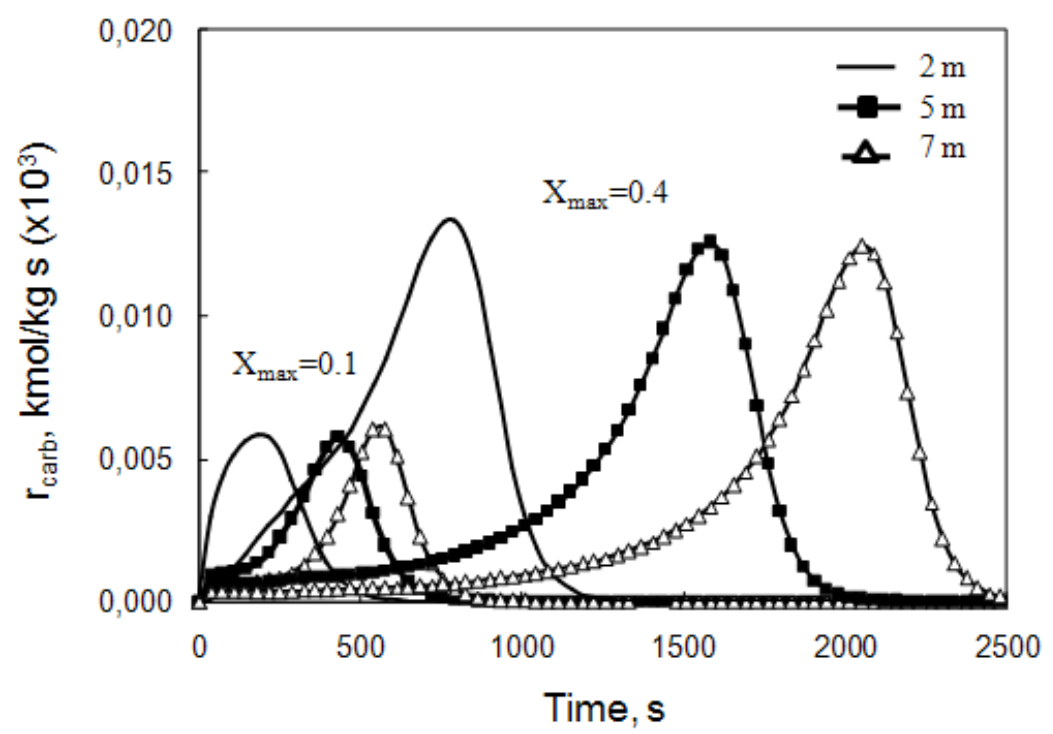


Fig. 8. Effect of carbonation kinetics on the product gas composition on a dry basis and on the temperature profile with the reaction time on stream (at the conditions shown in Table 3: $923 \mathrm{~K}, 3.5 \mathrm{MPa}, \mathrm{S} / \mathrm{C}$ molar ratio of 5).
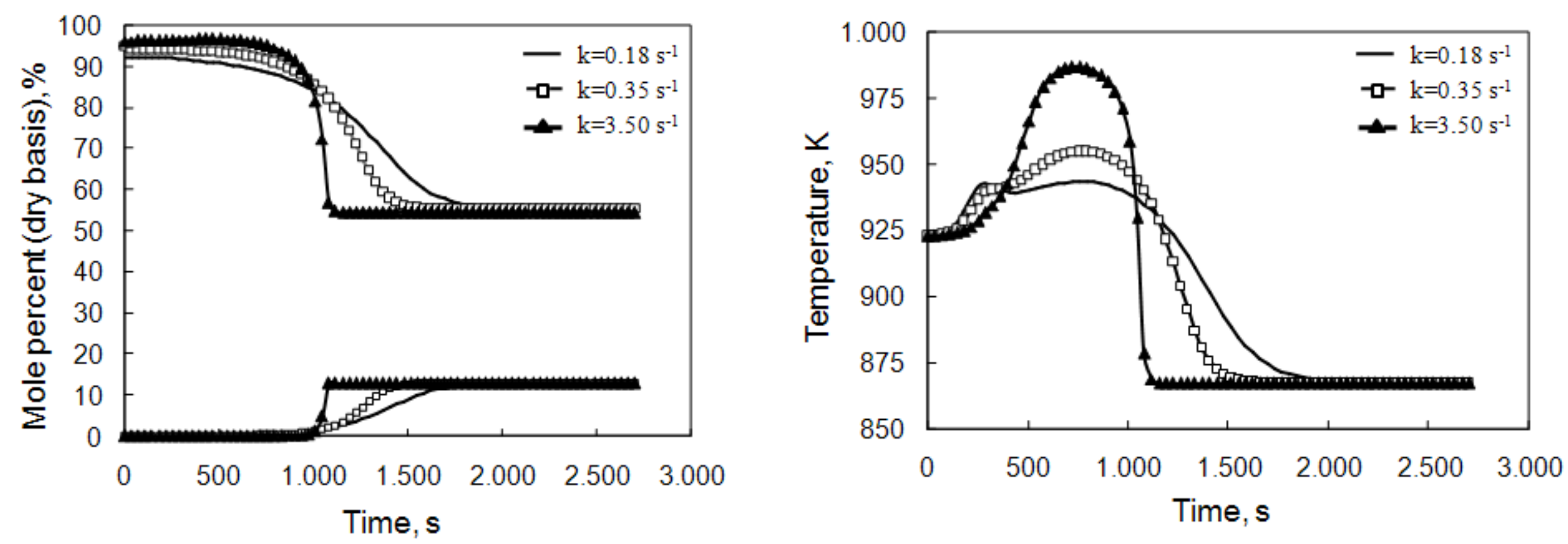
Fig. 9. Effect of carbonation rate constant on carbonation rate at different locations along the reformer (at the conditions shown in Table 3: 923 $\mathrm{K}, 3.5 \mathrm{MPa}$, S/C molar ratio of 5).

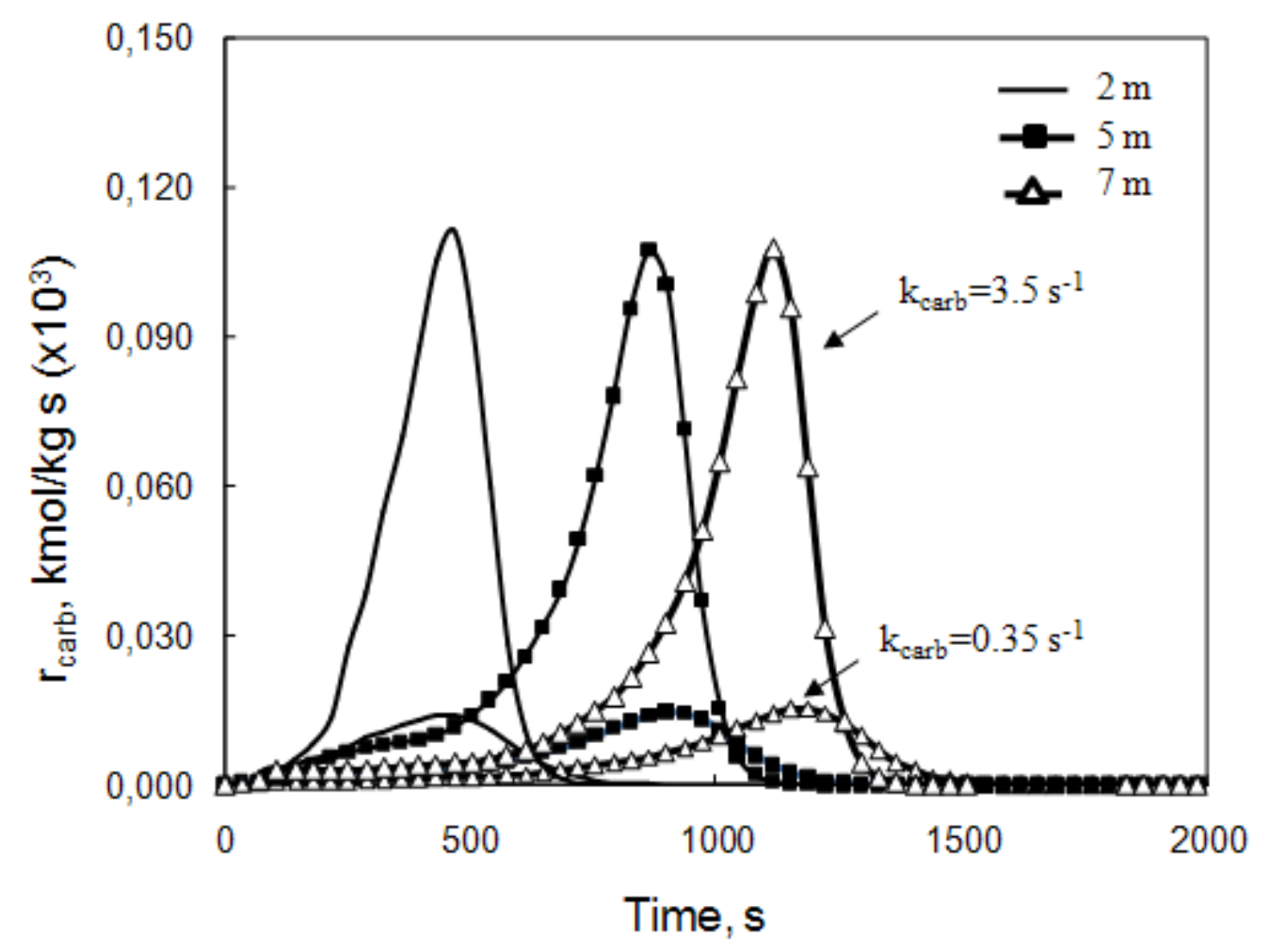


Fig. 10. Effect of carbonation rate constant on SER operational space velocities (923 K, 3.5 MPa, S/C molar ratio of 5).
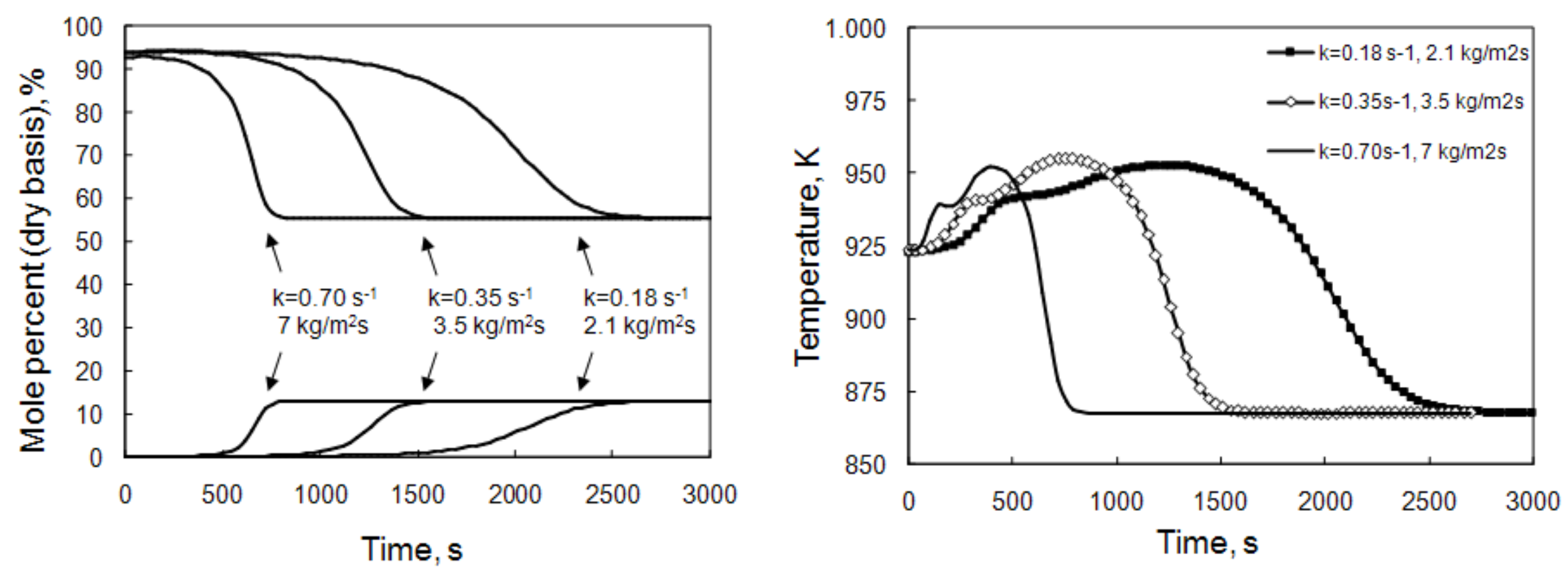
Table 1. Kinetic and equilibrium parameters in steam methane reforming $(\mathrm{Xu}$ and Froment, 1989; Twigg, 1989).

$$
\begin{aligned}
& \mathrm{K}_{1}=\frac{1}{\exp \left(0.2513 Z^{4}-0.3665 Z^{8}-0.58101 Z^{2}+27.1337 Z-3.2770\right)} \mathrm{atm}^{2} \mathrm{a} \\
& \mathrm{K}_{8}=\exp \left(-0.29353 Z^{8}+0.63508 Z^{2}+4.1778 Z+0.31688\right) \\
& z=\frac{1000}{T}-1 \\
& \mathrm{~K}_{2}=\mathrm{K}_{1} \mathrm{~K}_{3}
\end{aligned}
$$

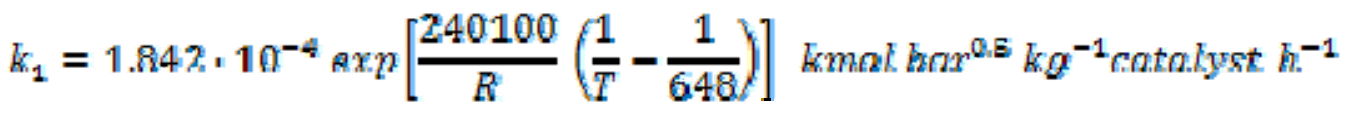$$
k_{2}=2.193 \cdot 10^{-8} \exp \left[\begin{array}{cc}
243900 \\
R
\end{array}\left(\begin{array}{cc}
1 & 1 \\
T & 648
\end{array}\right)\right] \text { hmol bar }{ }^{08} k g^{-1}{ }_{\text {eatalyst }} h^{-1}
$$

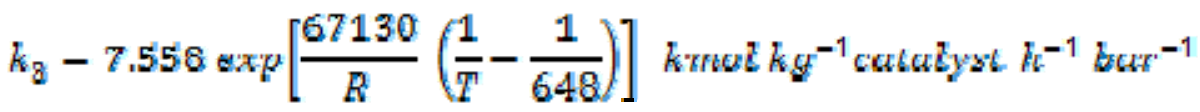$$
K_{C H 4}=0.179 \exp \left[\frac{38280}{R}\left(\frac{1}{T}-\frac{1}{823}\right)\right] \forall a r^{-1}
$$$$
K_{H 2 O}=0.4152 \exp \left[\frac{R R 6 R \Omega}{R}\left(\frac{1}{T}-\frac{1}{823}\right)\right]
$$$$
K_{H 2}=0.0296 \exp \left[\frac{82200}{R}\left(\frac{1}{T}-\frac{1}{648}\right)\right] \operatorname{bar}^{-1}
$$$$
K_{C O}=40.91 \exp \left[\frac{70650}{R}\left(\frac{1}{T}-\frac{1}{648}\right)\right] \operatorname{bar}^{-1}
$$

\footnotetext{
${ }^{a}$ Taken from Twigg (1989). The data reported by Xu and Froment (1989) are as follows: $\mathrm{K}_{1}=4.70710^{12} \exp (-224000 / \mathrm{RT}) \mathrm{bar}^{2}, \mathrm{~K}_{3}=1.14210^{-2} \exp (37300 / \mathrm{RT})$ (obtained for $\mathrm{T}=948 \mathrm{~K})$.
} 
Table 2. Physical parameters used in the reactor model.

\begin{tabular}{ll}
\hline Parameters & Values \\
\hline $\mathrm{M}_{\mathrm{CaO}}$ & $56 \mathrm{~kg} / \mathrm{kmol}$ \\
$\mathrm{C}_{\mathrm{pg}}$ & $8.45 \mathrm{~kJ} / \mathrm{kg} \mathrm{K}$ \\
$\mathrm{C}_{\mathrm{ps}}$ & $0.98 \mathrm{~kJ} / \mathrm{kg} \mathrm{K}$ \\
$\mu_{\mathrm{g}}$ & $1.8110^{-5} \mathrm{~kg} / \mathrm{m} \mathrm{s}$ \\
$\mathrm{k}_{\mathrm{g}}$ & $310^{-5} \mathrm{~kW} / \mathrm{m} \mathrm{K}$ \\
\hline
\end{tabular}


Table 3. Reactor characteristics and operating conditions for the reference case study.

\begin{tabular}{ll}
\hline Parameters & Values \\
\hline Feed gas temperature, $\mathrm{T}_{\text {in }}$ & $923 \mathrm{~K}$ \\
Initial solids temperature, $\mathrm{T}_{0}$ & $923 \mathrm{~K}$ \\
Pressure & $3.5 \mathrm{MPa}$ \\
S/C molar ratio & 5 \\
Inlet gas mass flow velocity & $3.5 \mathrm{~kg} / \mathrm{m}^{2} \mathrm{~s}$ \\
$\mathrm{X}_{\max }$ & 0.4 \\
$\eta$ & 0.3 \\
$\rho_{\text {cat }}$ & $550 \mathrm{~kg} / \mathrm{m}^{3}$ \\
$\rho_{\text {CaO }}$ & $1125 \mathrm{~kg} / \mathrm{m}^{3}$ \\
$\rho_{\mathrm{s}}$ & $1675 \mathrm{~kg} / \mathrm{m}^{3}$ \\
$\mathrm{~d}_{\mathrm{p}}$ & $0.01 \mathrm{~m}$ \\
$\mathrm{~L}$ & $7 \mathrm{~m}$ \\
$\varepsilon$ & 0.5 \\
\hline
\end{tabular}

